\title{
MOTIVATIONS IN ROMANTIC RELATIONSHIPS: A REGULATORY FOCUS PERSPECTIVE
}

\author{
A Thesis \\ by \\ HEIKE A. WINTERHELD
}

\author{
Submitted to the Office of Graduate Studies of \\ Texas A\&M University \\ in partial fulfillment of the requirements for the degree of \\ MASTER OF SCIENCE
}

May 2004

Major Subject: Psychology 


\title{
MOTIVATIONS IN ROMANTIC RELATIONSHIPS: A REGULATORY FOCUS PERSPECTIVE
}

\author{
A Thesis \\ by
}

HEIKE A. WINTERHELD

\author{
Submitted to Texas A\&M University \\ in partial fulfillment of the requirements \\ for the degree of \\ MASTER OF SCIENCE
}

Approved as to style and content by:

Jeff Simpson
(Chair of Committee)

Mike Stephenson

(Member of Committee)

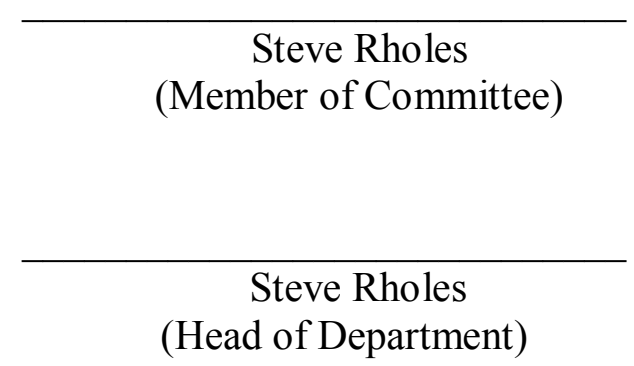

May 2004

Major Subject: Psychology 


\begin{abstract}
Motivations in Romantic Relationships: A Regulatory Focus Perspective. (May 2004)

Heike A. Winterheld, Tierarzt, Ludwig-Maximilians-University, Munich, Germany

Chair of Advisory Committee: Dr. Jeff Simpson
\end{abstract}

The present research tested whether and how regulatory focus as a motivational variable influences the ways in which people appraise, process, and react to events in romantic relationships. Regulatory focus theory distinguishes between (1) a prevention focus, which emphasizes the fulfillment of security needs, duties and obligations, and is associated with heightened sensitivity to aversive outcomes, and (2) a promotion focus, which emphasizes the fulfillment of nurturance needs, accomplishments and aspirations, and is associated with heightened sensitivity to rewarding outcomes. Based on regulatory focus theory, it was assumed that promotion and prevention focused people would appraise, react to, and process interpersonal events involving a romantic partner in different ways. In addition, it was expected that the distinct ways of experiencing such events are reflected in differences in relationship quality. Three studies using college student samples were conducted to test these notions. Evidence was found that individual differences in chronic prevention focus affect the ways in which people react to aversive events in relationships. No support was obtained for regulatory focus theory's predictions regarding prevention focus processes in association with rewarding outcomes, and predictions related to the promotion focus system were also not supported. As expected, chronic promotion focus 
was related to higher relationship quality, and chronic prevention focus was associated with lower relationship quality. Implications and suggestions for future research are discussed. 


\section{DEDICATION}

To my mother, Elvira R. Heinrich-Winterheld. 


\section{ACKNOWLEDGMENTS}

I thank my advisor, Jeff Simpson, for his methodological and theoretical guidance, for helping me clarify my murky ideas, and for being a consistent source of support and encouragement. It is not being taken for granted. I thank Steve Rholes for taking the time to endure my tangled thoughts, for suggestions on how to improve this project, and for valuable advice on where to go from here. I thank Mike Stephenson for his thoughtful input, encouragement, and for always making me feel welcome. I thank Laura Koehly for her statistical advice on this project.

I thank Carol Wilson for being a great friend and colleague, and I thank her and Becky Bodorvsky for being a tremendous source of support during a particularly trying time in my life. I thank SiSi Tran, Melissa Witt, Jeff Quinn, Minda Oriña, and Jon Iuzzini for their support and good humor during the past few years.

Finally, I thank my mother for teaching me that difficult times can be the start of amazingly positive transformations. I miss her love, laughter, and encouragement more than anything. 
TABLE OF CONTENTS

Page

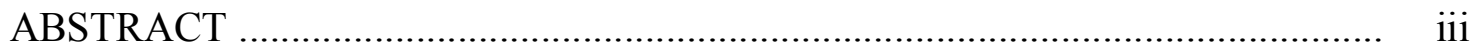

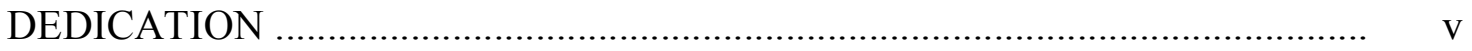

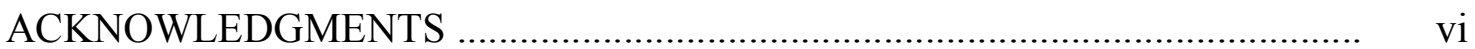

TABLE OF CONTENTS .............................................................................. vii

LIST OF TABLES _........................................................................... ix

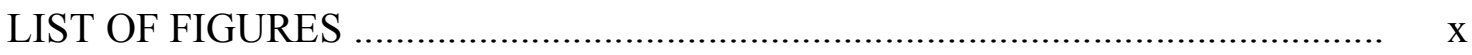

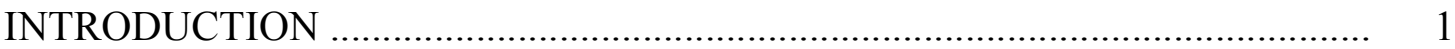

Approach and Avoidance Motivations .......................................................... 2

Motivational Processes in the Context of Romantic Relationships .............. 4

Regulatory Focus Theory ……………………………............................ 6

A Review of Research on the Impact of Regulatory Focus ........................ 10

Research Overview ............................................................................ 13

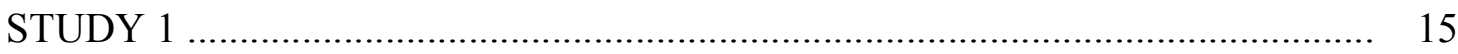

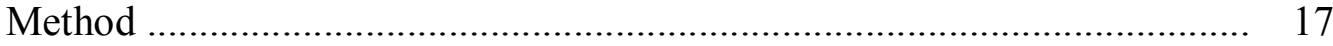

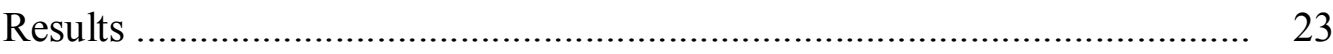

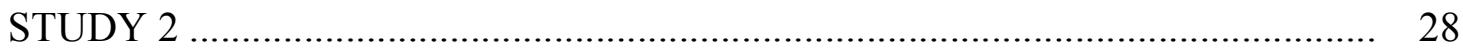

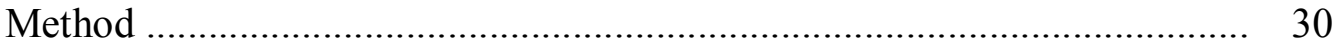

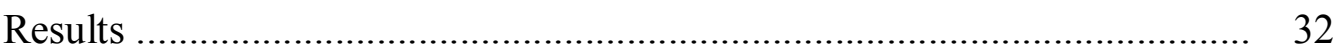

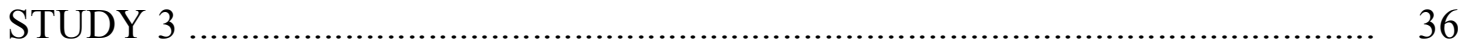

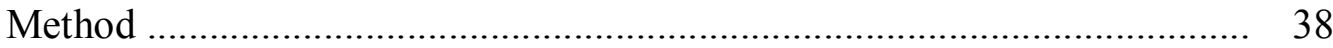

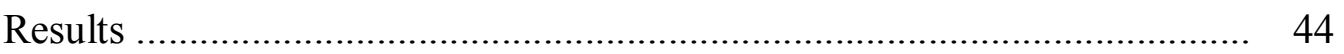

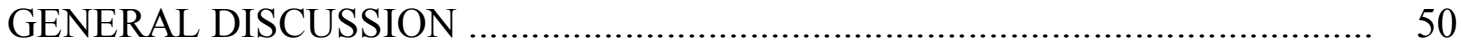

Regulatory Focus Differences in the Explanation of Interpersonal Events .. 50 Regulatory Focus Differences in the Affective Experience of Interpersonal Events ............................................................................. 51 
Regulatory Focus Differences in the Processing of Interpersonal Information and in Perceived Relationship Quality ................................ 52

Integration and Interpretation of Results ........................................... 53

Exploratory Analyses and Unexpected Findings .................................. 56

Limitations .................................................................................... 58

CONCLUSIONS AND FUTURE DIRECTIONS ….................................... 61

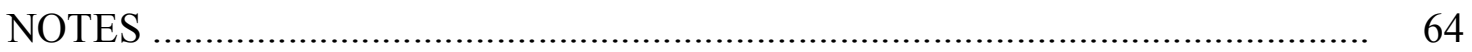

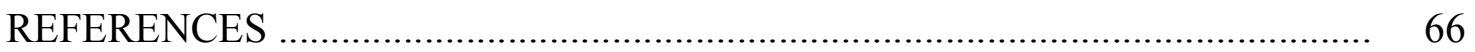

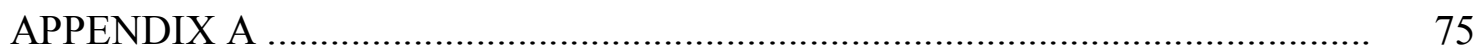

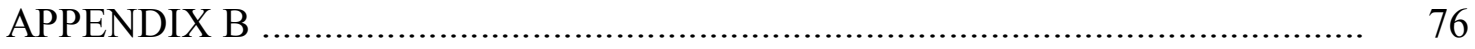

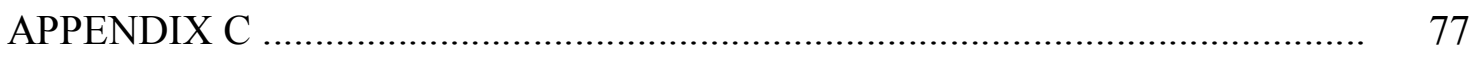

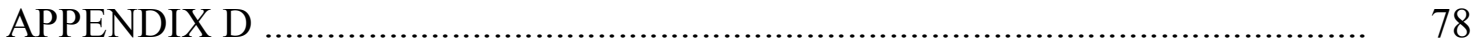

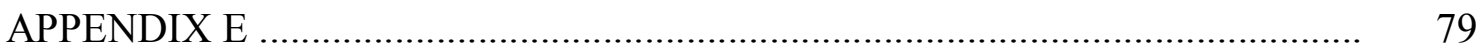

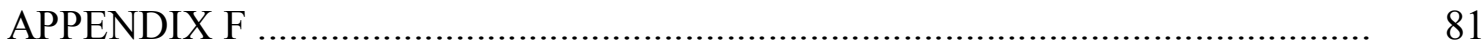

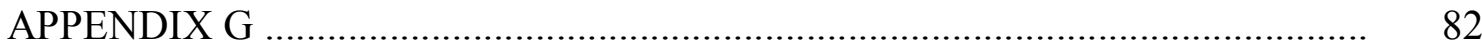

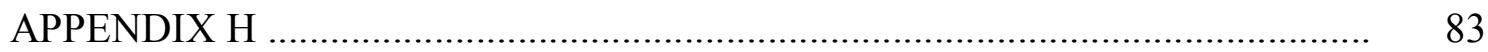

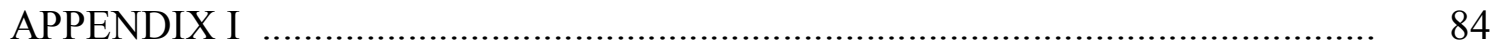

VITA 


\section{LIST OF TABLES}

Page

TABLE

1 Means and Standard Deviations for Perceived Likelihood

Ratings of Differently Framed Outcomes by High vs. Low

Promotion and Prevention Focused Participants

2 Mean Numbers and Standard Deviations of Types of Behaviors and Types of Outcomes as a Function of Chronic

Regulatory Focus and Prime

3 Correlation Matrix for Chronic Regulatory Focus and Perceived Relationship Quality 


\section{LIST OF FIGURES}

Page

FIGURE

1 Perceived likelihood of differently framed outcomes as a function of chronic prevention focus in the negative partner response condition ............................................................ 26

2 Recall as a function of chronic prevention focus in the

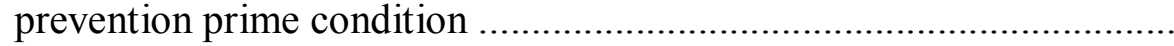




\section{INTRODUCTION}

Imagine two people who are in love with each other. Both would like to build and maintain a successful relationship. Although both partners have the same positive goal regarding their relationship, their underlying motivation associated with it may differ. One partner may be driven by the pleasure associated with attaining this goal ("I want us to be happy together") whereas the other may be more concerned with the pain following from not attaining it ("I don't want us to break up").

Such differing interpersonal motivations can give rise to divergent perceptions and appraisals of events in people's relationships, color people's subjective thoughts and emotions in response to these events in specific ways, and guide their behavior in specific ways to help them fulfill their social goals and needs (e.g., Baldwin, 1992; Berscheid, 1994; Collins \& Read, 1994; Mikulincer, 1998). The mechanisms, however, through which motivations can influence how people think, feel, and behave in their romantic relationships are not yet fully understood. A framework that may help us understand these mechanisms, but has not yet been applied to the context of romantic relationships is regulatory focus, a concept that distinguishes two separate forms of selfregulation (Higgins, 1997; 1998).

The purpose of this thesis is to explore how regulatory focus as a motivational principle is related to people's perceptions of, and responses to events in romantic relationships, and attempts to contribute to the understanding of people's variability in

This thesis follows the style and format of the Journal of Personality and Social Psychology. 
their psychological experience of the same event: why is it, for example, that some people interpret the postponement of a date by a partner as a major interpersonal setback, whereas others dismiss it as a foregone opportunity for shared fun? Why do some people get sad and others get angry in response to the same negative event in their relationship? Or, why do some people tend to actively approach or create opportunities for pleasurable social interactions with their romantic partners, whereas others are more likely to focus on avoiding painful ones?

In the following literature review some of the research converging on the notion that the processes underlying the hedonic principle of approaching pleasure and avoiding pain represent two independent processes will be introduced. Then, a model and research associated with motivational processes in interpersonal contexts will be presented, followed by a presentation of regulatory focus theory as an extension of the hedonic principle. Subsequently, selective but representative empirical evidence that different forms of self-regulation are associated with distinct psychological tendencies will be reviewed. The section will conclude with an overview of the studies conducted.

\section{Approach and Avoidance Motivations}

The hedonic principle of approaching pleasure and avoiding pain is central to most, if not all, motivational and behavioral self-regulation models (e.g., Gray, 1987; Atkinson, 1964; Carver \& Scheier, 1981). Much research suggests the existence of two functionally independent systems, one that regulates approach to potentially rewarding stimuli and desired outcomes (approach motivation), and one that regulates avoidance of potentially punishing stimuli and undesired outcomes (avoidance motivation) (e.g., 
Carver, 1996; Gray, 1987, 1994; Cacioppo, Gardner, \& Berntson, 1999; Cacioppo \& Berntson, 1994; Carver \& White, 1994).

For example, in their model of self-regulation, Carver and Scheier (1990) proposed that when a self-regulatory system has a desired end-state as a reference value, it reduces discrepancies by trying to move the current actual self-state as close a possible to the desired reference point. Conversely, when the reference point is an undesired point, the system amplifies discrepancies and attempts to move the current actual selfstate as far away as possible from the undesired reference point. Carver (1996) has equated the former discrepancy-reducing system with an approach system, and the latter discrepancy-amplifying system with an avoidance system.

Making a distinction between approach and avoidance goals, Elliot and colleagues have investigated self-regulation at the personal goal (Elliot \& Sheldon, 1998) and situation-specific level of analysis (Elliot \& Church, 1997), and found that approach and avoidance goals are associated with different antecedents and consequences (see also Elliot, 1999).

Gray $(1987 ; 1990 ; 1994)$ argues for two separate biologically-based systems that engender individual differences in the emotional and behavioral sensitivity to signals of reward and threat: the behavioral activation system (BAS) activates positive affect/hope and appetitive behavior in response to rewards (i.e., approach behaviors), and the behavioral inhibition system (BIS) invokes negative affect/anxiety and inhibits behavior in response to punishment and threat (i.e., avoidance behaviors). Extensive neurobiological and physiological research has supported Gray's proposition that these 
independent motivational dimensions reflect the operation of two separate neurobiological systems in the brain (e.g., Sutton \& Davidson, 1997; Harmon-Jones \& Allen, 1997; Sobotka, Davidson, \& Senulis, 1992).

In sum, the literature suggests that the hedonic principle of approaching pleasure and avoiding pain involves the operation of two independent systems, one responsible for regulating approach to positive outcomes, and one for the avoidance of negative outcomes.

\section{Motivational Processes in the Context of Romantic Relationships}

The fundamental hedonic principle of motivation can also be expected to operate in the context of relationships, particularly since relationships are arguably some of our greatest sources of both pleasure and pain (Gable \& Reis, 2001). Gable and Reis (2001) propose the existence of two separate systems: an appetitive system (akin to the approach system introduced in the previous section), and an aversive system (akin to the avoidance system). According to the authors, the two systems are conceptually and functionally independent, i.e., the processes involved in the attainment of positive, fulfilling relationship outcomes are likely to be distinct from those that regulate the avoidance of negative, distressing ones (see also Reis \& Gable, 2003).

In support of this proposition, Gable, Reis, \& Elliot (2000) have revealed in three diary studies that those who score higher on avoidance measures (i.e., those with higher BIS sensitivity) experience greater negative affect in their daily lives, most likely due to their amplified emotional reactions to actual or perceived negative events. Those with higher scores on approach measures (i.e., those with higher BAS sensitivity) experience 
more positive affect, presumably because they capitalize on perceived or actual opportunities conducive to positive social interaction.

Very recently, Gable (2003) has demonstrated that both dispositional approach motivations and current approach goals were reliably associated with less loneliness and more satisfaction in different types of close relationships over time. This association appears to be partially mediated by an increased exposure that approach-oriented people may have to positive events, which in turn serves their goals of having happier, more fulfilling social bonds. Conversely, Gable (2003) found that people's dispositional avoidance motivations and current avoidance goals were associated with increased loneliness, more negative social attitudes, and feelings of insecurity about their relationships. These associations seem to be partially mediated by the increased reactivity with which avoidance-oriented people respond to negative events when they inevitably occur.

Conceptualizing appetition/approach and aversion/avoidance as functionally distinct systems in relationships rather than as mirror images of each other (or endpoints on a single, continuous dimension) may help researchers identify and investigate favorable and detrimental processes in relationships, along with their respective antecedents and consequences (Reis \& Gable, 2003; Gable \& Reis, 2001). For example, avoiding a negative outcome (e.g., conflict) is different from not approaching a positive outcome (e.g., intimacy), and these processes are likely to be triggered by different circumstances and associated with different and discernible outcomes. 
Regulatory focus theory (Higgins, 1997; 1998) lends itself well to the investigation of the processes by which these independent mechanisms operate in interpersonal contexts. Even though Higgins' (1998) distinction between two separate forms of self-regulation is conceptually related to other approach/appetitiveavoidance/aversive motivation systems discussed earlier, it offers a more complete understanding of the hedonic principle by stipulating different ways in which people are motivated to seek pleasure and avoid pain. By specifying antecedents (e.g., needs and situations) of differential activation of the two motivational systems as well as by offering a rich description of the psychological tendencies associated with these differing motivational orientations, regulatory focus theory allows for more fine-grained predictions regarding the psychological processes by which approach and avoidance operate. For example, it may enable us to delineate situations or circumstances in which individuals respond to relationship events in ways that minimize negative outcomes or that maximize positive outcomes (Holmes, 2000). It may also allow us to investigate how situational antecedents interact with people's chronic motivational orientations, and thereby affect relationships outcomes.

\section{Regulatory Focus Theory}

For a more complete understanding of approach and avoidance, Higgins (1997; 1998) deems it essential to consider the different ways in which the hedonic principle operates. Thus, Higgins proposes an extension of the hedonic principle by suggesting distinct self-regulatory goals and the different ways in which they can be attained.

The basic assumption of regulatory focus theory (Higgins, 1997; 1998) is that the 
hedonic principle operates differently in the service of fundamentally different needs. Two such needs are nurturance needs and security needs, which serve separate survival functions (nourishment and protection, respectively).

To obtain the nurturance and security essential to their survival, children must build and maintain close relationships with responsive caregivers. In the context of these relationships, children need to learn how to behave in order to get their fundamental needs met (Bowlby, 1969; 1973). According to Higgins $(1997 ; 1998)$, what children learn about self-regulation differs for nurturance and security needs. He suggests that two qualitatively distinct motivational systems regulate the behaviors associated with attaining either nurturance or security as desired-end states.

Specifically, self-regulation toward nurturance needs involves a promotion focus, and self-regulation in relation to security needs involves a prevention focus. The higherlevel concerns arising from nurturance needs include advancement, growth, and accomplishment, whereas the higher-level concerns arising from security needs include protection, safety, and responsibility (see Maslow, 1955; Rogers, 1960; Bowlby, 1969).

How children learn to regulate themselves in relation to promotion- or prevention focus concerns and needs can be influenced by early interactions with their caregivers (Higgins \& Silberman, 1998). In interactions involving a promotion focus, children come to experience pleasure as the presence of positive outcomes (e.g., when the child is rewarded for accomplishments, encouraged to overcome obstacles, or provided with opportunities to engage in rewarding activities), and pain as the absence of positive outcomes (e.g., when caregivers withdraw love or attention, or act disappointed when 
the child does not fulfill the hopes/aspirations they have for him or her). Such interactions are presumed to convey that, in order to obtain the positive end-state of nurturance, one must focus on accomplishment and pursue hopes and aspirations (ideals).

In interactions involving a prevention focus, children experience pain as the presence of negative outcomes (e.g., when caregivers yell at or punish the child when he/she behaves irresponsibly), and pleasure as the absence of negative outcomes (e.g., when caregivers are overprotective, or alert the child to potential dangers in the environment). Such interactions are thought to communicate to the child that, in order to feel secure, one must ensure safety, be responsible, and fulfill duties and obligations (oughts).

Manian (2000) has provided empirical evidence for these assumptions, demonstrating that parents' chronic caregiver mode predicts children's dominant promotion versus prevention focus: nurturance-oriented parenting has been shown to encourage a promotion focus in children, whereas security-oriented parenting instills a prevention focus.

In sum, through early interactions with caregivers, children learn how to regulate themselves in relation to promotion and prevention concerns. Both regulatory focus systems are believed to coexist in every individual. However, depending on the predominant mode of caregiver-child interaction, one system should be chronically more accessible than the other in a given person. It is important to note that an individual can 
be socialized with both a promotion and a prevention focus, for example when multiple caregivers are involved (Higgins \& Silberman, 1998). ${ }^{1}$

In addition to varying chronically across individuals, regulatory focus can also be activated temporarily in momentary situations. For example, contemplating one's hopes and aspirations can activate a promotion focus, whereas reflecting on one's duties and obligations can induce a prevention focus (e.g., Liberman, Molden, Idson, \& Higgins, 2001; Liberman, Idson, Camacho, \& Higgins, 1999; Higgins, Roney, Crowe, \& Hymes, 1994).

Another antecedent of regulatory focus is the type of situation encountered. For example, positive situations can be framed as gains (e.g., by highlighting positive outcomes or possible rewards) or as non-losses (e.g., by highlighting averted losses or the absence of negative outcomes). In contrast, negative situations can be framed as losses (e.g., by highlighting negative outcomes or potential punishments) or as non-gains (e.g., by highlighting missed opportunities or the absence of positive outcomes). These frames of events or situations have been shown to differentially impact people's regulatory focus: communicating gain-related information, for example in the form of task instructions, induces a promotion focus, whereas communicating loss-related information induces a prevention focus (Brendl, Higgins, \& Lemm, 1995; Crowe \& Higgins, 1997; Higgins, Shah, \& Friedman, 1997).

To recap, a promotion focus fosters the fulfillment of nurturance needs, hopes and aspirations, and is concerned with accomplishment and personal growth. Comparable to approach-oriented people described earlier, promotion-focused people 
are highly sensitive to the presence and absence of positive outcomes (e.g., gains, rewards), and actively seek out and approach such opportunities. When in a promotion focus, one experiences pleasure or success when these outcomes are attained, and pain or failure when they are not attained.

A prevention focus, in contrast, facilitates the fulfillment of security needs, duties and obligations, and is concerned with safety. Similar to avoidance-oriented people, those who have a prevention focus are highly sensitive and reactive to the presence and absence of negative outcomes (e.g., losses, punishments), and actively try to avoid them. When in a prevention focus, one experiences pleasure or success when these outcomes are avoided, and pain when one cannot avert them.

\section{A Review of Research on the Impact of Regulatory Focus}

A rapidly growing literature has demonstrated that promotion and prevention foci, both chronic and situationally induced, are associated with differing perceptual sensitivities to positive and negative outcomes, distinctive emotional experiences and behavioral strategies. Those who adopt a promotion focus (chronically or temporarily) scrutinize/search their social world for information relevant to the attainment of positive outcomes, and are thus especially likely to attend to and recall events reflecting the presence and absence of positive outcomes (Higgins \& Tykocinski, 1992; Higgins et al. 1994). Consistent with their sensitivity to positive outcomes, both chronically and temporarily promotion focused people also remain open to change, and choose novel alternatives over old satisfactory options if these alternatives offer an advancement/gain over former ones (Liberman et al., 1999). Crowe and Higgins (1997) found that people 
display riskier styles of cognitive processing when a promotion focus is experimentally induced (e.g., people generate more novel alternatives during problem solving tasks). Moreover, both chronically promotion focused people and those with a momentarily induced promotion focus have been shown to generate and endorse more hypotheses for interpersonal actions, and take person and situation explanations into account when drawing inferences about others' behavior (Liberman et al., 2001).

In addition, people in a chronic and situationally induced promotion focus experience positive outcomes with greater intensity than those in a prevention focus, and the emotions underlying this greater intensity tend to be cheerfulness-related emotions (i.e., active positive emotions such as happiness). Negative outcomes, on the other hand, are felt less intensely, and with more dejection-related emotions (i.e., passive negative emotions such as disappointment) (Idson, Liberman, \& Higgins, 2000; Higgins, et al., 1997).

Furthermore, chronically and temporarily promotion focused people display more approach-related behaviors, approach matches to desired end-states (e.g., pursuing all means of advancement to attain their goals; Higgins et al., 1994), use more eagerness means (i.e., tactics that will advance goal attainment; Higgins et al., 2001), and show greater motivation and persistence on tasks that are promotion-framed (Shah, Higgins, \& Friedman, 1997).

In contrast, those who harbor a prevention focus (chronically or temporarily) scrutinize/search their social world for information relevant to the avoidance of negative outcomes, and are thus especially prone to attend to and recall events reflecting the presence and absence of negative outcomes (Higgins \& Tykocinski, 1992; Higgins et al., 
1994). In line with their concern for safety and security, both chronically and temporarily prevention focused people are more resistant to change and prefer to stick with old reliable options, even when new ones might work better (Liberman, et al., 1999). Crowe and Higgins (1997) found that people display more conservative styles of cognitive processing when a prevention focus is experimentally induced. In addition, both chronically prevention focused people and those with a momentarily induced prevention focus generate and endorse fewer hypotheses for interpersonal actions, and differentiate between person and situation explanations when drawing inferences about others' behavior (Liberman et al., 2001).

People in a chronic and situationally induced prevention focus state also experience negative outcomes more intensely than promotion-oriented people do, and the emotions underlying this greater intensity are agitation-related emotions (i.e., active negative emotions such as anger or anxiety). Positive outcomes are experienced less intensely and with more quiescence-related emotions (i.e., passive positive emotions such as calmness; Idson et al., 2000; Higgins et al., 1997). In terms of behavioral features, those in a chronic or situationally induced prevention focus are more likely to engage in avoidance-related behaviors, are more inclined to avoid mismatches to desired end-states (e.g., carefully avoiding any mistakes; Higgins et al., 1994), prefer vigilance means (i.e., not using tactics that might impede goal attainment; Higgins et al., 2001), and show greater motivation and persistence on tasks that are prevention-framed (Shah, et al., 1997). 
The reviewed perceptual, emotional, and behavioral tendencies associated with promotion and prevention focus may also shape what partners think, feel, and do in the context of their romantic relationships. This possibility has yet to be examined.

\section{Research Overview}

The purpose of the present research is to test how regulatory focus as a motivational principle influences the ways in which people appraise, process, and react to events and experiences in their romantic relationships.

On the basis of Regulatory Focus Theory (Higgins, 1997; 1998) preventionfocused people (i.e., people who are concerned with safety and strongly motivated to avoid negative outcomes) should be particularly attuned to social interactions or events that could denote the presence of losses, such as the loss of love from a significant other, conflict, rejection, or abandonment. In contrast, promotion-focused people (i.e., those who are concerned with advancement and strongly motivated to approach positive outcomes) should be particularly sensitive to social interactions or events that may signify the presence of gains, such as opportunities for personal growth with a partner, intimacy, and shared fun.

Because prevention- and promotion focused people operate on the basis of different motivations, they should appraise, process, and react to the same interpersonal events in different ways. Three studies were conducted to test these notions. Study 1 tested whether regulatory focus guides the appraisal and subjective interpretation of a relationship relevant event. Study 2 examined whether differences in regulatory focus are associated with variations in emotional experience to the same interpersonal event. Study 3 tested 
whether differences in regulatory focus lead people to preferentially attend to and recall information that is consistent with their regulatory focus. 


\section{STUDY 1}

Previous research (e.g., Crowe \& Higgins, 1997; Higgins et al., 1994) has shown that people who harbor a chronic promotion focus are sensitive to the presence and absence of positive outcomes (gains and non-gains), and those with a chronic prevention focus are sensitive to the presence and absence of negative outcomes (losses and nonlosses). Study 1 was designed to examine whether this differential sensitivity to gains/nongains and losses/non-losses that presumably springs from people's chronically accessible promotion or prevention concerns extends to romantic relationships. Based on previous research demonstrating that chronically accessible categories can influence the interpretation of ambiguous behavior (e.g., Bargh \& Pietromonaco, 1982; Srull \& Wyer, 1979), it was assumed that regulatory focus effects on sensitivity to positive and negative outcomes should be particularly pronounced when interpersonal situations or interactions are ambiguous and thus open to subjective interpretation.

Consistent with their sensitivity to the presence and absence of negative outcomes that they are trying to avoid or minimize, chronically prevention focused people should be more likely to interpret ambiguous interpersonal events as losses/setbacks (presence of a negative outcome), or as non-losses (absence of a negative outcome or averted loss). In contrast, because they show heightened sensitivity to the presence and absence of positive outcomes that they are trying to maximize, people with a chronically accessible promotion focus should be more likely to interpret ambiguous interpersonal situations as gains/opportunities for advancement (presence of a positive outcome), or as non-gains (absence of a positive outcome or missed opportunity). This differential subjective 
explanation of events should be reflected in increased perceived likelihood of loss-framed outcomes (relative to gain-framed outcomes) in a relationship scenario by highly prevention focused people, and in increased perceived likelihood of gain-framed outcomes (relative to loss-framed outcomes) by highly promotion focused people.

To test these notions, participants' chronic differences in regulatory focus were measured, and they were presented with a scenario describing the way in which a fictional person postpones a dinner date with his/her significant other. To make the event ambiguous and leave it open to interpretation, the scenario highlighted that the reason for the postponement was circumstantial (due to a friend in need).

In one condition, the scenario had two possible outcomes that both portrayed a negative reaction by the partner who had just received the news of the postponement of the date: one was loss-framed (the partner was angry and felt rejected), and one was nongain- framed (the partner was simply disappointed about the missed opportunity). In another condition, the same scenario had two possible outcomes that both described a more benevolent partner response: one was gain-framed (the partner was happy that his/her significant other was being a good friend), and one was non-loss framed (the partner was relieved that the date was only postponed rather than cancelled).

In both conditions, participants rated the extent to which they believed each outcome would occur based on their own expectations. Those participants with a strong prevention focus were expected to rate the loss-framed outcomes (i.e., loss and non-loss framed) as more likely to occur than low prevention focused people. Conversely, highly 
promotion focused participants should rate the gain-framed outcomes (i.e., gain and nongain framed) in both conditions as more likely to occur than those low in promotion focus.

To examine the impact of general chronic promotion and prevention focus independent of any specific romantic relationship that may involve a particular regulatory focus, both dating and non-dating participants were recruited. To minimize potential activation of momentary regulatory focus and allow for participants' chronic orientations to be projected onto the scenarios, participants were asked to respond to scenarios involving a fictional couple (rather than imagining themselves in the situation).

\section{Method}

\section{Participants}

Two hundred and fifty-nine undergraduate students at Texas A\&M University were recruited in exchange for extra credit in their introductory psychology course. Data from 12 participants were discarded because they failed to follow instructions, leaving a sample of 247 participants (131 men and 116 women). Participants ranged in age from 17 to 24 years, with a mean age of 18.85 years $(S D=.96)$. Eighty-three percent of participants were Caucasian, 11\% were Hispanic, 2\% were Asian American, 2\% were African-American, and were $2 \%$ of other, unspecified ethnic origin. To participate, it was required that participants be either currently involved in a romantic relationship or that they have been involved in a romantic relationship in the past. ${ }^{2}$ Twenty-two percent of participants reported to be currently single, $59 \%$ reported that they were currently dating a partner exclusively, $17 \%$ reported that they were dating a current partner and others, $2 \%$ reported being engaged, and one participant was married. 


\section{Materials}

Background Questionnaire. Participants were asked to answer several demographic questions and several questions about their dating status (see Appendix A).

Regulatory Focus Measure. Participants' chronic regulatory focus was assessed by a modified version of the Regulatory Focus Questionnaire by Lockwood, Jordan and Kunda (2002) (see Appendix B). According to Lockwood et al. (2002), items in the original measure assess the theoretical constructs used by Higgins and colleagues (see Shah, et al., 1998; Förster, Higgins, \& Idson, 1998; Idson, et al., 2000; Higgins et al., 2001), who have previously measured promotion and prevention focus by calculating difference scores between participants' ideal and ought self-guide accessibility (assessed by individuals' response times to questions about their self-guide attributes). Accessibility of ideal and ought self-guides is believed to indicate the strength of these self-guides, which involve promotion and prevention foci, respectively. Highly promotion focused people are concerned with accomplishment, hopes, and aspirations, and are thus likely to have readily accessible ideal self-guides (representing the type of person they would ideally like to be). In contrast, highly prevention focused people are concerned with safety, duties, and responsibilities, and are thus likely to have more accessible ought self-guides (representing the type of person they believed they ought to be; see Higgins, 1998). Lockwood et al.'s (2002) regulatory focus measure consists of 18 items designed to assess chronic promotion and prevention concerns in life in general. For the present study, this measure was modified to tap participants' chronic promotion and prevention goals/concerns that they have about their romantic 
relationships. All items were rated on a 9-point Likert-type scale (anchored 1= Not at all true of me and $9=$ Very true of $m e$ ). To create subscales measuring promotion and prevention focus, the item responses were submitted to an exploratory factor analysis (EFA), using principal-axis factoring and orthogonal (varimax) rotation. ${ }^{3}$ Two factors were extracted, accounting for almost $44 \%$ of the variance. The first factor had high loadings (> .4) on items related to promotion concerns (items $3,4,5,6,8,12,14,16,17$, 18), and the second factor had high loadings on items tapping prevention concerns (items $2,4,7,9,10,11,13,15$ ). One hypothesized prevention item (item 1) was deleted because it loaded on the promotion factor, and one item (item 15) was deleted because it failed to load highly on any factor. The two factors were moderately correlated, $r=.32$, $p<.01$. Participants' item responses were averaged to compute separate prevention focus and promotion focus scores for each person. Each of the scales exhibited good internal reliability (Cronbach's alpha $=.87$ for the promotion focus scale, and .81 for the prevention focus scale). Participants were identified as high or low in promotion focus using a median split on the 10-item promotion scale, and as high or low in prevention focus using a median split on the 6-item prevention scale. The median split of both the promotion scale, $\chi^{2}(1, N=247)=.40, p=.52$, and the prevention focus scale did not result in any sex differences between the groups, $\chi^{2}(1, N=247)=.49, p=.48$. To examine the construct validity of Lockwood et al.'s (2002) modified regulatory focus measure used in this study, it was correlated with the Regulatory Focus Questionnaire (RFQ) that assesses individuals' subjective histories of success or failure in promotion and prevention self-regulation with a promotion and a prevention subscale, respectively 
(see Higgins et al., 2001, for details). The two promotion scales were positively correlated, $r=.32, p<.01$, the two prevention scales, however, were not correlated. Adult Attachment Questionnaire. Promotion and prevention focus orientations have been conceptually related to attachment dimensions (Mikulincer \& Shaver, 2001; Smith, Murphy, \& Coats, 1999). Attachment anxiety and chronic prevention focus, for example, are associated, perhaps due to similar developmental antecedents (e.g., a parenting history of punishment and overprotection). Because of their inflated need for security and preoccupation with negative outcomes/losses such as abandonment, highly anxious individuals tend to have greater chronic prevention concerns in relationshiprelevant situations. To discount the possibility that the hypothesized results are attributed to shared variance with attachment orientations participants also completed the Adult Attachment Questionnaire (AAQ; Simpson, Rholes, \& Phillips, 1996; see Appendix C). The AAQ is a 17-item measure that asks respondents to indicate how they relate to romantic partners in general. Individuals respond on a 7-point Likert-type scale ( $1=$ strongly disagree; 7 = strongly agree). The AAQ is comprised of an avoidance scale and an ambivalence-anxiety scale. Cronbach's alpha $=.76$ for the avoidance scale, and .81 for the ambivalence-anxiety scale. In this study, chronic prevention focus and anxious attachment were in fact positively correlated, $r=.46, p<.01$, and chronic promotion focus and avoidant attachment were negatively related, $r=-.27, p<.01$.

Big Five. Individual differences in the responsivity of the approach system (including positive emotionality and promotion concerns) and the avoidance system (including negative emotionality and prevention concerns) should be conceptually 
related to the personality dimensions of extraversion and neuroticism, respectively (see Carver, Sutton, \& Scheier, 2000). In this study, extraversion was positively correlated with chronic promotion focus, $r=.20, p<.01$, and negatively with chronic prevention focus, $r=-.15, p<.05$; neuroticism was positively correlated with chronic prevention focus, $r=.34, p<.01$, and not correlated with chronic promotion focus. To discount the possibility that the current results might be due to shared variance with these personality dimensions, participants also completed Goldberg's (1990) Big Five Scale (see Appendix D). Each item was answered on a 5-point Likert-type scale (anchored 1= strongly disagree, $5=$ strongly agree). Cronbach's alpha $=.83$ for the extraversion subscale, and .77 for the neuroticism subscale.

Stimulus Materials. Participants read a scenario that described how one partner postponed a dinner date with his/her significant other for circumstantial reasons (due to a friend in need). The scenario had two possible outcomes that referred to the response of the partner who had just been informed by his/her significant other about the postponement of the date (see Appendix E). In one condition ("negative partner response"), both outcomes portrayed a negative reaction by the partner: one was lossframed (the partner was angry and felt rejected), and one was non-gain framed (the partner was disappointed about the missed opportunity). In another condition ("benevolent partner response"), the two outcomes described a more benevolent reaction by the partner: one was gain-framed (the partner was happy that his/her significant other was being a good friend), and one was nonloss-framed (the partner was relieved that the date was only postponed rather than cancelled). 


\section{Dependent Measure}

The dependent measure in Study 1 was participants' perceived likelihood that the differently framed outcomes would occur. Specifically, participants were asked to indicate how likely the occurrence of each outcome would be. Ratings were made on a 7-point scale with anchors labeled 0 (Not likely at all) and 7 (Very likely).

\section{Procedure}

Participants reported to an experimental room where they were run in mixedgender groups of 10-15 people. Participants were separated by at least two seats to ensure privacy and independence of responses. They first read and signed a consent form and were told by the experimenter that the purpose of the study was to examine "how people explain events that occur in relationships". They were further told that would be completing a battery of questionnaires and would then be asked to respond to a short hypothetical scenario. After completing the questionnaires, participants were randomly assigned to receive one of the two previously described conditions. Participants were asked to carefully read and then respond to their scenario. Finally, participants were fully debriefed and thanked for their participation.

Design

Study 1 was a 2 (promotion focus: high vs. low) x 2 (prevention focus: high vs. low) $\mathrm{x} 2$ (condition: negative vs. benevolent partner response) $\mathrm{x} 2$ (outcome frame: gain vs. loss-related) mixed design, with the first three variables as between-subjects factors and the last variable as a within-subjects variable. Approximately an equal number of participants were randomly assigned to the two partner response conditions. 


\section{Results}

Means and standard deviations for perceived likelihood ratings of the differently framed outcomes are displayed in Table 1. The first set of analyses tested whether there were any effects of gender, attachment avoidance or anxiety, and the personality dimensions of extraversion or neuroticism on the dependent measure. The latter four variables were not significantly associated with the dependent measure, either singularly or interactively. ${ }^{4}$ Only one non-interpretable five-way interaction between gender, promotion focus, prevention focus, condition, and outcome frame was found. To test for the effects of chronic regulatory focus on participants' perceived likelihood of the differently framed outcomes, a 2 (promotion focus: high vs. low) x 2 (prevention focus: high vs. low) x 2 (condition: negative vs. benevolent partner response) x 2 (outcome frame: gain vs. loss-related) mixed analysis of variance (mixed ANOVA) with the first three variables as between-subjects factors and the last variable as a within-subjects variable was performed..$^{5}$ 
Table 1

Means and Standard Deviations for Perceived Likelihood Ratings of Differently Framed Outcomes by High vs. Low Promotion and Prevention Focused Participants

\begin{tabular}{|c|c|c|c|c|c|c|c|c|}
\hline & \multicolumn{4}{|c|}{ Benevolent partner response } & \multicolumn{4}{|c|}{ Negative partner response } \\
\hline & \multicolumn{2}{|c|}{$\begin{array}{l}\text { Gain-framed } \\
\text { outcome }\end{array}$} & \multicolumn{2}{|c|}{$\begin{array}{l}\text { Nonloss-framed } \\
\text { outcome }\end{array}$} & \multicolumn{2}{|c|}{$\begin{array}{l}\text { Loss-framed } \\
\text { outcome }\end{array}$} & \multicolumn{2}{|c|}{$\begin{array}{l}\text { Nongain-framed } \\
\text { outcome }\end{array}$} \\
\hline & $M$ & $(S D)$ & $M$ & $(S D)$ & $M$ & $(S D)$ & $M$ & $(S D)$ \\
\hline Promotion low & 2.69 & $(1.77)$ & 5.21 & $(1.45)$ & 2.95 & $(1.80)$ & 5.52 & $(1.64)$ \\
\hline Promotion high & 2.89 & $(2.02)$ & 5.72 & $(1.44)$ & 2.82 & $(1.84)$ & 5.57 & $(1.38)$ \\
\hline Prevention low & 2.87 & $(1.93)$ & 5.60 & $(1.33)$ & 2.56 & $(1.75)$ & 5.84 & $(1.29)$ \\
\hline Prevention high & 2.72 & $(1.88)$ & 5.35 & $(1.58)$ & 3.17 & $(1.84)$ & 5.28 & $(1.65)$ \\
\hline
\end{tabular}

A significant main effect for outcome frame revealed that, overall, participants rated nonloss and nongain framed outcomes as more likely than gain and loss framed outcomes, $F(1,231)=218.41, p<.001, \eta^{2}=.49 .^{6}$

More importantly, the expected significant three-way interaction between prevention focus, condition, and outcome frame, $F(1,231)=6.42, p<.012, \eta^{2}=.03$, as well as a marginally significant interaction between promotion focus, condition, and outcome frame, $F(1,231)=3.28, p<.072$, emerged. ${ }^{7}$ To decompose the significant three-way interaction, tests for simple interaction effects were conducted (Keppel, 1991; Winer, Brown, \& Michels, 1991; for example, the prevention focus x outcome frame 
interaction was analyzed for each condition separately). To control for inflated Type I error rates due to multiple testing, a Bonferroni-type adjustment was made. The significance values obtained from four tests were rank-ordered from smallest to largest. The significance of the first test was evaluated at alpha / number of tests (i.e., alpha $=$ $.05 / 4=.013$ ), the second test at alpha $/$ number of tests -1 (i.e., alpha $=.05 / 3=.017$ ), the third test at alpha / number of tests -2 (i.e., alpha $=.05 / 2=.025$ ), and the last test at alpha $/$ number of tests -3 (i.e., alpha $=.05 / 1=.05)$ (Holland \& Copenhaver, 1988) In the negative partner response condition, a 2 (prevention focus: high vs. low) $\mathrm{x}$ 2 (outcome frame: gain vs. loss-related) ANOVA revealed a significant interaction between prevention focus and outcome frame, $F(1,114)=6.76, p=.011, \eta^{2}=.06$ (see Figure 1). In the benevolent partner response condition, the prevention focus $\mathrm{x}$ outcome frame interaction was not significant, $F(1,117)=.75, p=.39$. A non-interpretable interaction between outcome, sex, promotion and prevention focus also emerged, $F$ (1, $117)=7.93, p=.006$. 


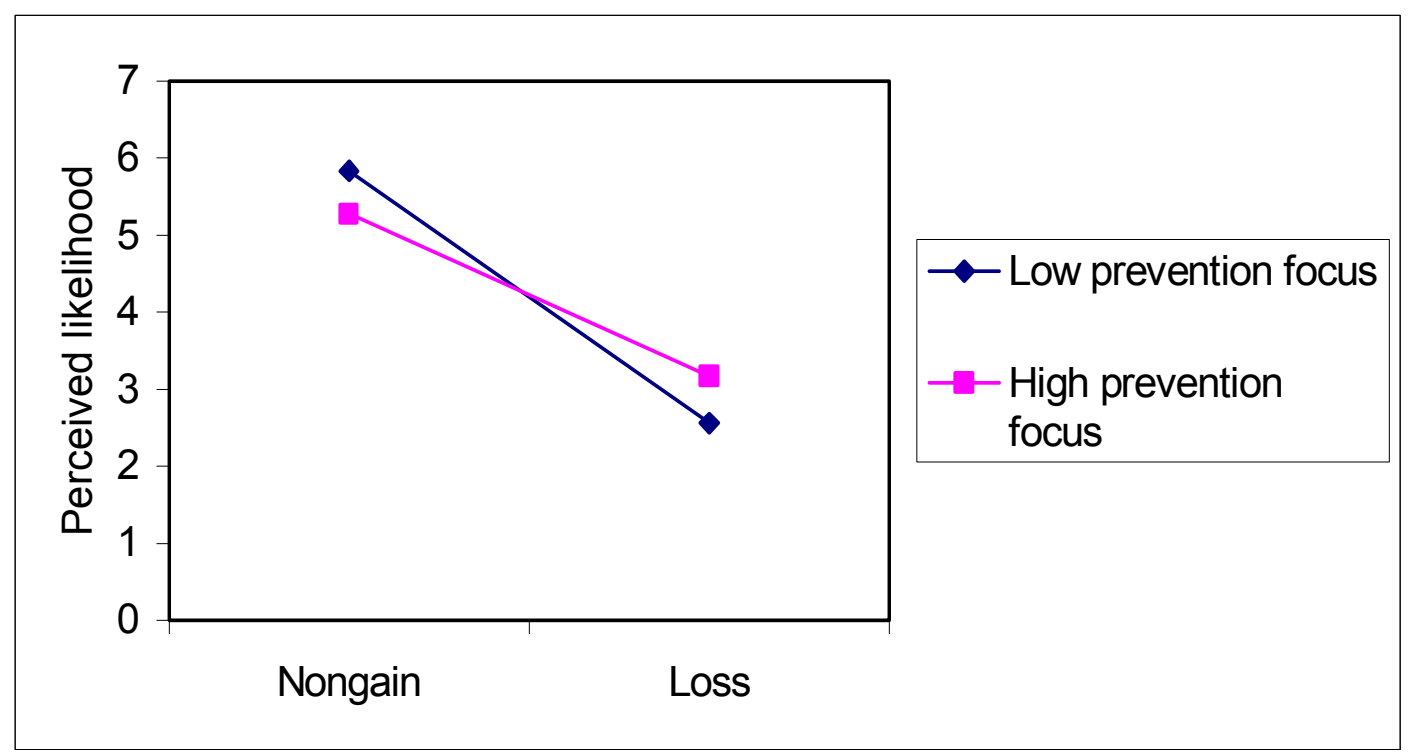

Figure 1. Perceived likelihood of differently framed outcomes as a function of chronic prevention focus in the negative partner response condition.

To investigate the significant two-way interaction further, tests for simple main effects by outcome were conducted within the negative partner response condition (Keppel, 1991). A one-way, between subjects ANOVA revealed that highly prevention focused participants rated the loss-framed outcome more likely than those with a low prevention focus, $F(1,114)=5.93, p=.016, \eta^{2}=.05$. Highly prevention focused participants did not rate the nongain-framed outcome as less likely than those with a low prevention focus, $F(1,114)=4.06, p=.046$ (not significant according to the Bonferronitype adjustment).

The results of Study 1 did not support the prediction that participants with a 
chronic promotion focus should be more inclined to expect gain-phrased events involving a positive or a negative partner reaction. The prediction that highly prevention focused participants should be inclined to view an event involving a positive partner response as a non-loss was also not supported. However, the results of Study 1 suggest that, consistent with their vigilance to negative outcomes, participants with a chronic prevention focus tend to perceive an event involving a negative reaction by a fictional romantic partner as a loss as more likely than do those who do not have a strong prevention focus.

Regulatory focus may also be revealed in ways other than the presumed probability of different types of outcomes following a relationship-relevant event. It might, for instance, be revealed by people's affective experiences in gain-and lossrelated situations (e.g., Higgins, 1997; 1998). Study 2 examined this possibility in the context of romantic relationships. 


\section{STUDY 2}

Because people with different regulatory orientations differ in the way in which they interpret events, they may also differ in their emotional response to different events. According to regulatory focus theory, people who have adopted a promotion focus (both chronically or situationally induced) tend to construe outcomes as maximal goals (aspirations) that they hope to attain, whereas those in a prevention focus are more likely to represent outcomes as minimal goals (duties, obligations) that they must attain (see Brendl \& Higgins, 1996). Thus, the pleasure of attaining a desired outcome in a promotion focus (promotion success or gain experience) should be greater than the pleasure of attaining the same positive outcome in a prevention focus (prevention success or nonloss experience). Conversely, the pain of failing to attain the same outcome in a prevention focus (prevention failure or loss experience) should be greater than when in a promotion focus (promotion failure or nongain experience). Idson et al. (2000) have provided empirical support for these predictions by demonstrating that participants feel better about outcomes framed as gains (getting a discount) than as nonlosses (not paying a penalty), and that they feel worse about outcomes framed as losses (paying a penalty) than as non-gains (not getting a discount). This research, however, was not conducted in the context of romantic relationships.

In addition, previous research has identified the types of emotions associated with both temporarily induced (e.g., Idson et al. 2000) and chronically salient regulatory foci (e.g., Idson et al., 2000; Higgins, et. al., 1997). In these studies, the greater intensity of pleasure felt by those in a promotion focus in response to positive outcomes was 
experienced as relatively high-intensity cheerfulness-related pleasure, compared to the more low-intensity quiescence-related pleasure experienced by prevention focused participants. Moreover, the greater intensity of pain experienced by prevention-focused participants in response to negative outcomes was experienced as relatively highintensity agitation-related pain, compared to the weaker dejection-related pain felt by participants with a promotion focus.

In most of these studies, affective regulatory focus effects have been examined as responses to material gains/nongains and losses/nonlosses (e.g., gaining or losing points, winning or losing games) or to gain-or loss-framed task feedback on achievement tasks. Study 2 was designed to test whether the pattern of emotional responses predicted by regulatory focus theory also emerges when gains/nongains and losses/nonlosses occur in a relationship context.

According to regulatory focus theory, people possess both promotion and prevention systems and, over and above chronic individual differences in regulatory focus, certain situations (such as the presence or absence of gain/reward-related stimuli or loss/punishment-related stimuli) can trigger one or both systems to varying degrees (Higgins, 1998). Based on theory and research (Higgins, 1998), it was predicted that the pattern of emotional responses described above would emerge when the frame of the relationship scenario was consistent with participants' chronic regulatory orientation. Specifically, highly promotion focus participants, compared with low promotion focus participants should feel happier/more cheerful in response to a gain-framed scenario, and more disappointed/sad in response to a nongain-framed scenario. Highly prevention 
focused participants, on the other hand, should feel more anger/agitation than those with a low prevention focus in response to a loss-framed scenario, and more satisfied/pleased in response to a nonloss-framed scenario.

According to Brendl et al. (1995), however, little or no affective discrimination should be expected when participants' chronic orientation is inconsistent with situationally activated regulatory focus. Regulatory focus theory proposes that the promotion and prevention systems ought to be independent, resulting in mutual inhibition of these systems when they are simultaneously active (Brendl et al., 1995; Higgins, 1998).

\section{Method}

\section{Participants}

The sample for Study 2 was the same sample as in Study 1. Care was taken to convey to participants that this was an entirely separate study, which was conducted by a different experimenter. Data from nine participants were discarded because they did not answer the dependent measure, leaving a sample of 238 participants (123 men and 115 women).

Materials

Regulatory Focus Measure, Adult Attachment Questionnaire, Big 5 Scale. These measures were the same as in Study 1.

Vignettes. Regulatory focus was manipulated by language that emphasized either gain/non-gain or loss/non-loss related outcomes. To increase the personal relevance of the scenarios, participants were asked to imagine themselves in the situation. 
Specifically, participants were presented with scenarios in which the critical feature was a vacation that one could or could not spent with one's significant other (see Appendix F). The gain-framed scenario highlighted that a positive outcome (gain: having a good time with one's partner by being able to go on the vacation with him/her) was attained or was not attained (nongain: missing out on a good time with one's partner by not being able to go on the vacation). The loss-framed scenarios contained outcomes of the same magnitude (i.e., one could or could not spend a vacation with the partner). However, in the loss-framed scenario, a negative outcome either transpired (loss: one had to disappoint the partner by not being able to go on the vacation) or was avoided (nonloss: one did not have to disappoint the partner because one could go on the vacation). Procedure

Participants were told by an experimenter that they would take part in a study on "how people react to relationship events". They were first asked to complete a brief questionnaire unrelated to the present study. They were then asked to read a short scenario, imagine the prospective outcome of the scenario, and rate how they would feel about the outcome if they were in that situation. Participants were randomly assigned to receive one of four conditions: gain, non-gain, loss, or non-loss. After completing the materials, participants were fully debriefed and thanked for their participation.

\section{Dependent Measure}

The subjective emotional ratings in response to the vignettes were the dependent measures. Participants rated the extent to which they felt specific emotions on a ninepoint scale, with endpoints labeled 0 (Not at all) and 9 (A great deal). The specific 
emotions used were selected so that the four major quadrants presumed to underlie the experience of emotions in response to various promotion- and prevention outcomes were represented (see Higgins, et al., 1997; Idson et al., 2001). The happiness associated with promotion success (gain) was tapped by 'happy' and 'cheerful', the quiescence associated with prevention success (nonloss) by 'content' and 'pleased', the tenseness presumed to underlie prevention failure (loss) was tapped by 'angry' and 'agitated', and the dejection in response to promotion failure (nongain) by 'sad' and 'disappointed'. Design

Study 2 had a 2 (promotion focus: high vs. low) x 2 (prevention focus: high vs. low) x 4 (condition: gain, nongain, loss, nonloss) x 4 (emotion type: tenseness, dejection, happiness, quiescence) mixed design, with the first three factors serving as betweensubjects variables, and the last factor being a within-subjects variable.

\section{Results}

Preliminary analyses indicated that participants' ratings of the eight emotions were highly correlated $(r>.78)$. Therefore, they were combined into four emotion indices. With regard to the promotion focus relevant emotions, the positive emotions happy and cheerful were combined into an index labeled Happiness, and the negative emotions sad and disappointed were combined into an index labeled Dejection. With regard to the prevention focus relevant emotions, the positive emotions content and pleased were combined into an index labeled Quiescence, and the negative emotions angry and agitated were combined into an index labeled Tenseness (e.g., Idson et al., 2000; Higgins, Shah \& Friedman, 1997). 
Moreover, preliminary analyses tested whether there were any effects of gender, attachment avoidance or anxiety, and the personality dimensions of extraversion or neuroticism on the dependent measure. Neither main effects nor interaction effects involving attachment orientations or extraversion and neuroticism were found. ${ }^{8}$

The analysis revealed a significant sex $\mathrm{x}$ condition $\mathrm{x}$ emotion type interaction, $F(9,205)=3.11, p=.014, \eta^{2}=.04$. Tests for simple interaction effects by condition were performed, and a significant interaction between sex and emotion in the nonloss condition emerged, $F(3,57)=5.93, p=.012, \eta^{2}=.09$. Based on tests for simple main effects conducted on each type of emotion, women experienced significantly more happiness-related emotions $(M=17.65, S D=.71)$ in the nonloss condition than did men $(M=14.22, S D=5.85), F(1,57)=7.74, p=.007, \eta^{2}=.12$.

To test for the effects of chronic regulatory focus on participants' emotional responses to the differentially framed scenarios, the data were analyzed using a 2 (promotion focus: high vs. low) x 2 (prevention focus: high vs. low) x 4 (condition: gain, nongain, loss, nonloss) x 4 (emotion type: tenseness, dejection, happiness, quiescence) mixed-model analysis of variance (mixed ANOVA). Emotion type was a within-subjects variable, and the remaining three variables were between-subjects variables. ${ }^{9}$

The ANOVA revealed a significant condition $\mathrm{x}$ emotion type interaction, $F(9$, 203) $=354.54, p<.001, \eta^{2}=.84$, such as that people reported more dejection-related emotions $(M=15.81, S D=2.76)$ than tenseness-related emotions $(M=12.65, S D=$ 4.30) in response to the loss scenario. None of the two predicted three-way interactions (i.e., promotion focus $\mathrm{x}$ condition $\mathrm{x}$ emotion type, and prevention focus $\mathrm{x}$ condition $\mathrm{x}$ 
emotion type) were significant, $F(9,205)=1.73, p=.14$, and $F(9,205)=1.01, p=.40$, respectively.

For exploratory reasons, separate one-way, between-subjects ANOVAs were conducted on the emotions predicted to be experienced by high vs. low promotion focused participants in gain-related situations, and by high vs. low prevention focused participants in loss-related situations. Because of inflated Type I error rates due to multiple testing, a Bonferroni-type adjustment was made. The significance values obtained from four tests were rank-ordered from smallest to largest. The significance of the first test was evaluated at alpha / number of tests (i.e., alpha $=.05 / 4=.013$ ), the second test at alpha / number of tests -1 (i.e., alpha $=.05 / 3=.017$ ), the third test at alpha / number of tests -2 (i.e., alpha $=.05 / 2=.025)$, and the last test at alpha / number of tests -3 (i.e., alpha $=.05 / 1=.05)$ (see Holland \& Copenhaver, 1988).

A one-way between-subjects ANOVA in the gain condition revealed that participants high in promotion focus $(M=16.88, S D=3.44)$ did not feel more happiness-related emotions than those low in promotion focus $(M=17.13, S D=1.20)$, $F(1,60)=.09, p=.75$. Also, highly promotion focused participants did not feel more dejection-related emotions $(M=15.59, S D=2.35)$ in the nongain condition compared to low promotion focused participants $(M=13.97, S D=3.96), F(1,55)=3.49, p=.078$.

In the nonloss condition, highly prevention focused participants did not experience more quiescence-related emotions $(M=15.62, S D=4.77)$ than low prevention focused participants $(M=15.20, S D=4.76), F(1,55)=.13, p=.72$. However, participants with a strong prevention focus experienced more tenseness- 
related emotions $(M=14.33, S D=3.08)$ in the loss condition than did low prevention focused participants $(M=11.03, S D=4.70), F(1,51)=6.92, p=.011, \eta^{2}=.12$.

When interpreting the individual dependent variables separately by condition, Study 2 revealed that highly prevention focused participants reported more tensenessrelated emotions such as anger and agitation in response to a loss-framed relationship event. Taken together, the findings from Studies 1 and 2 seem to suggest that, compared to low prevention focused participants, highly prevention focused participants tend to subjectively interpret an interpersonal event as a loss (relative to a nongain), and also seem to react more strongly to it.

Studies 1 and 2 examined the impact of chronic and situational regulatory focus on subjective interpretation and emotional experience. The purpose of Study 3 was to investigate how people with chronically accessible and situationally manipulated promotion and prevention concerns process information that is compatible vs. incompatible with their dominant focus. 


\section{STUDY 3}

People may process information that is consistent with their self-regulatory goals more carefully and systematically than information that is not compatible with these goals (Higgins, 2000; Lee \& Aaker, 2004). A promotion focus involves heightened sensitivity to the presence and absence of positive outcomes, and those who have a promotion focus (chronic or situationally induced) are especially likely to attend to and recall information involving such outcomes. A prevention focus (chronic or situationally induced), in contrast, involves increased sensitivity to the presence and absence of negative outcomes, leading those with a prevention focused state to be more likely to notice and recall information involving negative outcomes (Higgins et al., 1994; Aaker \& Lee, 2001). Higgins and Tykocinski (1992), for instance, found that people with a chronic promotion focus had better memory for events in which another person experienced or did not experience positive outcomes; those with a chronic prevention focus, however, showed improved memory for events in which a target person encountered or did not encounter aversive outcomes.

Furthermore, to ensure positive outcomes and to guard against their absence, promotion focused people rely on approach behavior (e.g., looking for means of advancement). Conversely, prevention focused people use avoidance strategies because they allow them to ensure the absence of negative outcomes and guard against their presence (e.g., carefully avoiding mistakes; Higgins, 1997; 1998). In support of this, Higgins et al. (1994) demonstrated that participants that were temporarily primed with a promotion focus showed better recall for episodes exemplifying approach strategies than 
those exemplifying avoidance strategies. The reverse was true for participants who were primed with a prevention focus.

In these studies, however, the effects of regulatory focus compatibility on recall were examined in everyday life contexts. For example, target persons in the episodes experienced general positive or negative outcomes (such as finding a $\$ 20$ bill or finding out that a favorite movie is not showing anymore), or relied on general approach or avoidance behaviors (such as signing up for a class or skipping a workout). Borrowing from Higgins and colleagues (Higgins \& Tykocinski, 1992; Higgins et al., 1994), Study 3 was designed to test whether the above-mentioned effects of regulatory focus on memory would also be obtained when presented in a more specific life region (i.e., in a romantic relationship).

If people pay more attention to and engage in more elaborative processing of relationship relevant information that is compatible vs. incompatible with their dominant regulatory focus, better recall of this information should result. Thus, participants with a chronic or primed promotion focus should show higher recall of information involving approach behavior and/or positive outcomes in a relationship than those low in promotion focus, and participants with a chronic or primed prevention focus should show higher recall of avoidance behavior and/or aversive outcomes than those with a low prevention focus. Because regulatory focus was operationalized as both a situational prime and as a chronic orientation, an interaction between prime and recall and two interactions between chronic regulatory focus and recall (i.e., one interaction between promotion focus and recall and one between prevention focus and recall) would provide 
clear support for these predictions.

Study 3 was also intended to explore how dispositional regulatory focus orientations may interact with situational activation of regulatory focus, although no specific predictions could be derived from regulatory focus theory per se. Potential three-way interactions between prime, regulatory focus, and recall could shed light on whether situational effects amplify or suppress chronic regulatory effects, or whether chronic orientations override situational activation of regulatory focus.

A final purpose of Study 3 was to explore how regulatory focus may be related to relationship quality. Higgins et al. (1994) demonstrated that prevention focused people selected interpersonal strategies geared toward avoiding negative outcomes in friendships. Although she did not examine romantic relationships, Gable (2003) showed that avoidance motives were associated with more insecurity in various social bonds. Thus, it was expected that a prevention focus might be associated with lower quality romantic relationships. A promotion focus, on the other hand, was assumed to be associated with higher relationship quality. Higgins et al. (1994) demonstrated that promotion focused people selected more friendship strategies intended to approach positive social outcomes, and Gable (2003) showed that approach motives are related to increased satisfaction with various social relationships.

\section{Method}

\section{Participants}

One hundred and sixty-seven undergraduate students at Texas A\&M University were recruited in exchange for extra credit in their introductory psychology course. Data 
from four participants were discarded because they failed to follow instructions, leaving a sample of 163 participants ( 86 men and 77 women). Participants ranged in age from 17 to 22 years, with a mean age of 18.67 years $(\mathrm{SD}=.87)$. Ninety-four percent of participants were Caucasian, $3 \%$ were Hispanic, 1\% were Asian American, $1 \%$ were AfricanAmerican, and 1\% were of other, unspecified ethnic origin. To participate, participants had to be currently involved in a romantic relationship. ${ }^{10}$ Ninety-two percent of participants reported that they were currently dating a partner exclusively, $6 \%$ reported that they were dating a current partner and others, and $2 \%$ reported being engaged. Relationship length ranged from 1 to 93 months, with a mean length of 13 months. Materials

Background Questionnaire. Participants were answered the same demographic background survey as in Study 1 (see Appendix A).

Regulatory Focus Measure. Participants' chronic regulatory focus was assessed with the same modified scale by Lockwoood et al. (2002) that was administered in Study 1 (see Appendix B). Participants' item responses were averaged to compute separate prevention focus and promotion focus scores for each person. Both subscales exhibited good internal reliability (Cronbach's alpha $=.84$ for the promotion focus scale, and .80 for the prevention focus scale), and were not highly correlated, $r=.21, p<.01$.

Participants were identified as high or low in promotion focus using a median split on the 10-item promotion scale, and as high or low in prevention focus using a median split on the 6-item prevention scale. The median split of the promotion scale, $\chi^{2}$ 
$(1, N=163)=.32, p=.16$, and the prevention focus scale did not produce any sex differences between the groups, $\chi^{2}(1, N=163)=1.09, p=.35$.

Relationship Quality Measure. To assess participants' relationship quality, they completed the Perceived Relationship Quality Components (PRQC) Inventory (Fletcher, Simpson, \& Thomas, 2000; see Appendix G). Participants rated their romantic relationships on six subscales measuring relationship satisfaction (Cronbach's alpha = $.92)$, commitment (Cronbach's alpha $=.96)$, closeness (Cronbach's alpha $=.83)$, trust $($ Cronbach's alpha $=.89)$, passion $($ Cronbach's alpha $=.82)$, and love (Cronbach's alpha $=.91)$ on a 7-point Likert-type scale anchored 1 (Not at all) and 7 (Extremely).

Adult Attachment Questionnaire. To determine whether the hypothesized results might be attributed to shared variance with attachment orientations, participants completed the Adult Attachment Questionnaire (AAQ; Simpson, et al., 1996) (see Study 1 for details on this measure; Appendix C). Cronbach's alpha $=.79$ for the avoidance scale, and .79 for the ambivalence-anxiety scale. Prevention focus was positively correlated with anxious attachment, $r=.35, p<.01$, and with avoidant attachment, $r=$ $.18, p<.05$. Promotion focus was negatively correlated with avoidance, $r=-.21, p<.01$.

Big Five. To examine the possibility that the results might be due to shared variance with personality dimensions, participants completed Goldberg's (1990) Big Five Scale (see Study 1 for details; Appendix D). In Study 3, extraversion (Cronbach's alpha $=.79)$ was positively correlated with promotion focus, $r=.25, p<.01$, and neuroticism $($ Cronbach's alpha $=.78)$ was positively correlated with chronic prevention focus, $r=.34, p<.01$. 
Regulatory Focus Priming Manipulation. Participants were randomly assigned to receive either promotion focus priming or prevention focus priming (see Higgins et al., 1994). To induce a promotion focus, participants were asked to describe their hopes and goals for their current dating partner and romantic relationship, and how their hopes and goals have changed compared to those they had when they first started dating people. The prevention focus prime instructions asked participants to describe their sense of duty, responsibility, or obligation that they have to their current dating partner or current romantic relationship, and how this differed from the sense of duty, responsibility, or obligation they felt when they first started dating people. A blank page with the priming instructions on top (see Appendix H) was provided to each participant.

Episodes. All participants then read the same episodes that described what a target person (a fictional undergraduate student) experienced in his/her relationship with his/her romantic partner over four days (see Appendix I). To reduce gender confounds, the target person was male for male participants, and was female for female participants. In each of 16 episodes, the target was trying to either attain a positive outcome or avoid a negative outcome. To attain a positive outcome, the target relied on either approach or avoidance strategies. To avoid a negative outcome, the target used either approach strategies or avoidance strategies. To determine whether the episodes successfully represented the four categories, ten undergraduate students were asked to assign each of the 16 constructed episodes to one of the four categories. Fourteen episodes were each correctly assigned by all ten coders, and two episodes were correctly assigned by 8 coders. Each participant read a total of 20 episodes. For each day (identified as Day 1 to Day 4), five episodes were 
described, one of which was a neutral (relationship irrelevant) filler item. Filler items were included as a measure of general recall ability and were treated as a covariate in the analyses. The order of episodes was different for each participant. However, each day contained one episode in which the target used approach behaviors to attain a positive outcome, approach behavior to avoid a negative outcome, avoidance behavior to avoid a negative outcome, avoidance behavior to attain a positive outcome, and one filler item.

\section{Dependent Measure}

The dependent measure was participants' recall of the number of episodes containing approach strategies, avoidance strategies, positive outcomes, and negative outcomes.

Procedure

Participants reported to an experimental room where they were run in mixedgender groups of 10 persons. Participants were separated by at least two seats to ensure privacy and independence of responses. The experimenter told participants that they would participate in two ostensibly different studies. They were told that, because the first study was very short, it would be combined with a second study that was unrelated to the first one. They were further told that the purpose of the first study was to "examine how people's relationship standards change over time", and that the purpose of the second study was to "investigate the relationship between the perception of verbally described episodes and visual stimuli”. Participants then read and signed a consent form. The experimenter then instructed participants to complete a battery of questionnaires. After completing the questionnaires, participants were randomly assigned to either the 
prevention focus or the promotion focus prime condition. Participants spent approximately 10 minutes completing their responses to the primes. The experimenter thanked participants for completing this study, and a second experimenter then entered the room to supposedly conduct a second study.

The second experimenter told participants that, for the second study, which concerned the perception of verbally described episodes, they would read episodes from a diary of a Texas A\&M undergraduate student that occurred over 4 days in the student's life. They were instructed to read the episodes slowly and carefully, and to form an impression of what these days were like for the student. When all participants had finished reading the episodes, the experimenter introduced the "visual stimuli task". In reality, this task functioned as a distractor, and consisted of copying shapes for approximately 7 minutes. Following this, the experimenter passed out sheets of paper and told participants to remember and write down the diary episodes that they had just read as precisely as possible and in as much detail as they could. The experimenter emphasized that the order in which the episodes were recalled would not matter. Participants spent about 15 minutes completing the recall task. Finally, participants were fully debriefed and thanked for their participation.

\section{Coding of Recall Data}

Each participant's reproduced episodes were scored by two independent raters who were blind to participants' chronic regulatory focus and priming condition. The reproduced episodes were coded for the number of correctly recalled types of behaviors 
(approach behaviors and avoidance behaviors), and types of outcome (positive outcomes/approach goals and negative outcomes/avoidance goals). Participants'scores for each type of behavior and type of outcome could range from 0 through 8 . To assess interrater rater agreement, Cohen's kappa was calculated. High interrater agreement was obtained for both types of behaviors and types of outcomes. Cohen's kappa was .99 for approach behaviors, .96 for avoidance behaviors, .92 for positive outcomes, and .89 for negative outcomes.

Design

Study 3 was a 2 (chronic promotion focus: high vs. low) x 2 (chronic prevention focus: high vs. low) x 2 (prime: promotion vs. prevention) between subjects design in which behaviors (approach vs. avoidance) and valence of outcomes (positive vs. negative) were within-subjects variables.

\section{Results}

\section{Regulatory Focus and Recall}

Mean numbers of type of behaviors and type of outcomes recalled as a function of chronic regulatory focus and prime are displayed in Table 2. 
Table 2

Mean Numbers and Standard Deviations of Types of Behaviors and Types of Outcomes Recalled as a Function of Chronic Regulatory Focus and Prime

Promotion Prime

\begin{tabular}{lcccc}
\hline & \multicolumn{2}{c}{ Chronic Promotion Focus } & \multicolumn{2}{c}{ Chronic Prevention Focus } \\
& Low & High & Low & High \\
\cline { 2 - 5 } & & & & \\
Approach Behaviors & $3.38(1.44)$ & $3.77(1.52)$ & $3.24(1.50)$ & $3.88(1.43)$ \\
Avoidance Behaviors & $4.14(1.72)$ & $4.23(1.60)$ & $4.32(1.68)$ & $4.09(1.63)$ \\
Positive Outcomes & $6.86(2.99)$ & $5.24(2.86)$ & $6.89(3.18)$ & $7.07(2.15)$ \\
Negative Outcomes & $7.10(2.38)$ & $5.26(2.78)$ & $5.32(2.73)$ & $5.19(2.89)$ \\
\hline
\end{tabular}

Prevention Prime

\begin{tabular}{lcccc}
\hline & \multicolumn{2}{c}{$\begin{array}{c}\text { Chronic Promotion Focus } \\
\text { Low }\end{array}$} & High & \multicolumn{2}{c}{$\begin{array}{c}\text { Chronic Prevention Focus } \\
\text { Low }\end{array}$} & High \\
\cline { 2 - 5 } & & & & \\
Approach Behaviors & $3.80(1.47)$ & $3.95(1.64)$ & $3.93(1.50)$ & $3.83(1.61)$ \\
Avoidance Behaviors & $3.80(1.79)$ & $4.74(1.27)$ & $4.48(1.71)$ & $4.07(1.49)$ \\
Positive Outcomes & $7.36(3.33)$ & $7.93(2.50)$ & $8.00(2.85)$ & $6.85(2.83)$ \\
Negative Outcomes & $4.34(2.61)$ & $5.98(2.56)$ & $4.95(2.60)$ & $5.39(2.53)$ \\
\hline
\end{tabular}


To examine the effects of both chronic and situationally activated regulatory focus on participants' recall of types of behaviors and outcomes, a 2 (chronic promotion focus: high vs. low) x 2 (chronic prevention focus: high vs. low) x 2 (prime: promotion vs. prevention) x 2 (type of behavior: approach vs. avoidance) x 2 (valence of outcome: positive vs. negative) mixed analysis of variance (ANOVA) with the first three variables as between-subjects factors and the last two variable as a within-subjects variable was performed. ${ }^{11}$ The predicted interaction between prime and recall was not significant, $F$ $(3,155)=.96, p=.39$, indicating that the prime did not affect participants' recall. The interaction between chronic promotion focus and recall was also not significant, suggesting that highly promotion focused participants did not recall more approach behaviors and/or positive outcomes than low promotion focused participants, $F(3,155)$ $=.76, p=.48$. The interaction between chronic prevention focus and recall was marginally significant, $F(3,155)=2.86, p=.056 .^{12}$

The ANOVA showed a significant interaction between chronic prevention focus, prime and recall, $F(3,155)=3.02, p=.046, \eta^{2}=.02($ see Figure 2$)$. 


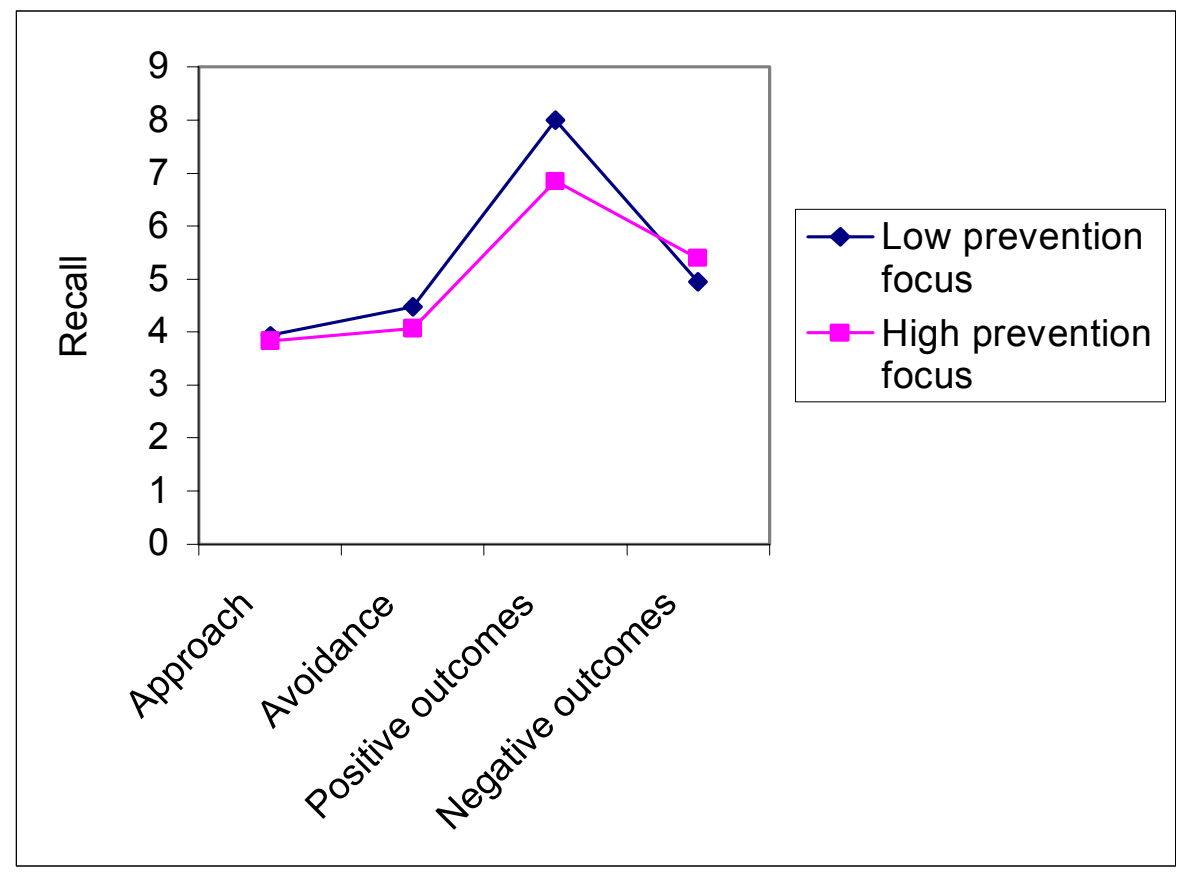

Figure 2. Recall as a function of chronic prevention focus in the prevention prime condition.

To decompose the interaction, tests for simple effects were performed. To reduce the risk of inflated Type I error rates due to multiple testing, a modified Bonferroni-type technique was used to determine the statistical significance of the simple effects analyses. The significance values obtained from six tests were rank ordered from smallest to largest. The significance of the first test was evaluated at alpha / number of tests (i.e., alpha $=.05 / 6=.008)$, the second test at alpha $/$ number of tests -1 (i.e., alpha $=.05 / 5=.010)$, the third test at alpha $/$ number of tests -2 (i.e., alpha $=.05 / 4=.013$ ), the fourth test at alpha / number of tests -3 (i.e., alpha $=.05 / 3=.017$ ), the fifth test at 
alpha / number of tests -4 (i.e., alpha $=.05 / 2=.025)$ and the last test at alpha $/$ number of tests -5 (i.e., alpha $=.05 / 1=.05)($ see Holland \& Copenhaver, 1988).

Simple interaction effects by prime condition revealed that the interaction between chronic prevention focus and recall was significant in the prevention prime condition, $F(3,79)=5.40, p=.003, \eta^{2}=.06$, but not in the promotion prime condition, $F(3,76)=.88, p=.42$. To investigate the significant two-way interaction further, tests for simple main effects by recall components (i.e., approach behaviors, avoidance behaviors, positive outcomes, and negative outcomes) were conducted in the prevention prime condition. A one-way between-subjects ANOVA revealed that, when exposed to a prevention prime, participants low in chronic prevention focus recalled more positive outcome information, whereas highly prevention focused participants recalled less, $F$ (3, 79) $=8.04, p=.006, \eta^{2}=.09$.

For exploratory reasons, the interaction between chronic promotion focus and recall was considered separately for each prime condition. It was not significant in the promotion prime condition, $F(3,76)=.10, p=.91$, but approached significance in the prevention prime condition, $F(3,79)=2.61, p=.07, \eta^{2}=.03$. The same modified Bonferroni-type adjustment described above was used to investigate simple main effects. A one-way between-subjects ANOVA revealed that, when exposed to a prevention prime, participants high in chronic promotion focus recall more aversive outcome information than low promotion focused participants, $F(3,79)=8.50, p=.005, \eta^{2}=$ .10 . 


\section{Regulatory Focus and Relationship Quality}

Correlational analyses were conducted to assess the association between regulatory focus and 6 perceived relationship quality components (Fletcher et al., 2000). As can be seen in Table 3, and supporting the predicted associations, participants with a chronic promotion focus reported higher satisfaction, commitment, trust, love, and closeness in their relationships. A prevention-focused disposition, on the other hand, was associated with lower satisfaction, less closeness and less trust in the relationship.

\section{Table 3}

Correlation Matrix for Chronic Regulatory Focus and Perceived Relationship Quality

\begin{tabular}{|c|c|c|}
\hline & \multicolumn{2}{|c|}{ Regulatory Focus } \\
\hline & Promotion focus & Prevention focus \\
\hline \multicolumn{3}{|c|}{ Relationship quality: } \\
\hline Satisfaction & $.34 * *$ & $-.26 * *$ \\
\hline Commitment & $.44 * *$ & -.09 \\
\hline Closeness & $.35^{* *}$ & $-.18^{*}$ \\
\hline Trust & $.35^{* *}$ & $-.20 * *$ \\
\hline Sex & .14 & -.09 \\
\hline Love & $.47 * *$ & -.09 \\
\hline
\end{tabular}

Note. $N=163$.

$* p<.05$. **p $<.01$. 


\section{GENERAL DISCUSSION}

The purpose of the present research was to investigate how regulatory focus as a motivational variable influences the ways in which people respond to events in romantic relationships. Based on regulatory focus theory, which proposes that prevention and promotion focused people operate according to different motivations, it was assumed that they would appraise, react to, and process interpersonal events in different ways. In addition, it was assumed that these distinct ways of experiencing events in relationships might be reflected in differences in relationship quality.

\section{Regulatory Focus Differences in the Explanation of Interpersonal Events}

Study 1 tested whether chronically accessible regulatory focus concerns would guide the subjective interpretation of an ambiguous interpersonal event, as reflected in the increased perceived likelihood of differently framed outcomes following this event. It was hypothesized that, consistent with their heightened sensitivity to the presence and absence of negative outcomes, individuals with a chronic prevention focus would be more likely to interpret ambiguous interpersonal events in loss-related terms. In contrast, due to their heightened sensitivity to the presence and absence of positive outcomes, individuals with a chronic promotion focus would be more likely to interpret interpersonal events in gainrelated terms.

High and low prevention focused participants did not differ in the presumed probability of a nonloss-framed outcome (depicting a mild positive response by a fictional partner who was relieved that a date was only postponed rather than cancelled) relative to a gain-framed outcome (depicting a strong positive response by a fictional partner who 
appreciates his/her significant other for postponing a date to help a friend in need). Participants with a strong chronic prevention focus did, however, rate a loss-framed outcome (depicting a strong negative response by a fictional partner who feels angry and rejected because of a postponed date) as more likely relative to a nongain-framed outcome (depicting a mild negative response by the same fictional partner who was disappointed about a postponed date, but not upset) compared to participants who were low in prevention focus.

Predictions with regard to a chronic promotion focus were not supported. High and low promotion focused participants did not differ in the perceived likelihood of a gainframed outcome relative to a nonloss-framed outcome, and they also did not differ in the perceived likelihood of a nongain-framed outcome relative to a loss-framed outcome.

Regulatory Focus Differences in the Affective Experience of Interpersonal Events

Study 2 examined the effects of chronic regulatory focus on participants' emotional responses to differentially framed scenarios that depicted gains/non-gains and losses/non-losses occurring in a hypothetical relationship. It was predicted that highly prevention focused participants would respond to loss-framed events with relatively greater quiescence or tenseness, and that highly promotion focused participants would respond to gain-framed events with relatively greater happiness or dejection.

When interpreting the individual univariates by condition, Study 2 revealed that highly prevention focused participants reported more tenseness-related emotions such as anger and agitation in response to a loss-framed relationship event compared to those with 
a low prevention focus. Highly prevention focused people did not, however, report more quiescence-related emotions in response to a nonloss-framed event.

Highly promotion focused participants, compared with low promotion focused participants, did not report to be happier in response to a gain-framed relationship event in a relationship, and they also did not report more dejection-related emotions in response to a nongain-framed event.

Regulatory Focus Differences in the Processing of Interpersonal Information and in Perceived Relationship Quality

Study 3 tested whether people engage in more elaborative processing of relationship-relevant information that is compatible vs. incompatible with their dominant regulatory focus (chronically accessible and situationally activated). It was expected that highly prevention focused individuals, compared to those low in prevention focus, would be more likely to attend to and recall information involving avoidance behaviors and/or aversive outcomes, and that highly promotion focused individuals would be more likely to attend to and recall information involving approach behaviors and/or desired outcomes compared to low promotion focused participants. No support was garnered for these predictions.

An additional purpose of Study 3 was to explore how regulatory focus may be related to romantic relationship quality. It was predicted that a chronic promotion focus would be associated with higher relationship quality, and that a chronic prevention focus would be associated with lower quality relationships. Both of these predictions were supported. 


\section{Integration and Interpretation of Results}

Overall, did participants in the present research respond to interpersonal events in ways that regulatory focus theory predicts? The answer appears to be affirmative for highly prevention focused people in response to negative events. Highly prevention focused people, however, did not respond to positive events as regulatory focus theory predicts, and there was also no support for regulatory focus theory's predictions regarding promotion focused individuals.

Consistent with their vigilance to negative outcomes, participants who were chronically high in prevention focus appeared to subjectively interpret events in a relationship as losses (Study 1), and tended to react more strongly to loss in a relationship than did low prevention focused people (Study 2). These findings fit well with previous work by Derryberry and Reed (1994) suggesting that high avoidance individuals are biased to focus on negative cues (especially those indicative of loss). The findings are also in line with more recent work on approach-avoidance motivations in social contexts. For example, Gable et al. (2000) reported that high avoidance-motivated people tend to experience greater negative emotions than low avoidance-motivated people in response to negative events, suggesting a heightened emotional reactivity to negative events by those who are high in avoidance motivation. Moreover, individuals with dominant avoidance motives and high fear of rejection reported negative social events to be highly important to them (Gable, 2003).

Compared to low prevention focused people, highly prevention focused people did not perceive a nonloss as more likely relative to a gain (Study 1), and they did not 
feel better about a nonloss depicted in a relationship context (Study 2). The scenario in Study 1 depicted an ambiguous situation in which one member of a couple postponed a date with the other for circumstantial reasons. Even though the benevolent partner response condition offered two positive outcomes, the mere statement that a date had been postponed may have increased prevention focused participants' already heightened vigilance to negative outcomes, rendering them less able to experience positive outcomes and to discriminate between them. In other words, even though a prevention focus is associated with heightened sensitivity to both the presence and absence of losses, the information about a postponed date may have made highly prevention focused participants disproportionately sensitive to the presence of losses relative to the absence of losses.

In Study 2, it might have been problematic for participants to imagine a prospective outcome as a nonloss (i.e., as something aversive that is not going to happen). There is evidence that it may be easier for people to imagine something that has happened vs. something that has not happened. Brendl, et al. (1995), for example, found that participants discriminated more between different amounts of gains and losses than between different amounts of nongains and nonlosses. This might have been one reason why no affective discrimination in the nonloss condition was made by prevention focused people.

Another possibility is that the dependent variables (i.e., the quiescence-related emotions "pleased" and "content") might not have captured how participants really felt. These emotions may be too closely related to happiness/joy and, thus, may not represent 
prevention focus relevant emotions very well. A superior descriptor of a nonloss experience may be "relieved" or, as others have suggested, "relaxed", "calm", or “comfortable". (see Lee, et al., 2000).

There are some logical reasons why virtually no promotion focus effects were found. Kluger (2000), who did not find promotion focus effects in a non-relationship context, suggests that regulatory foci may exist in a two-tier hierarchy. More specifically, due to their evolutionary advantage, a prevention focus should have priority in guiding psychological responses. Similar to Maslow's (1955) notion of hierarchy of needs, security needs should override needs for personal growth and nurturance. Perhaps the scenarios in Studies 1 and 2 brought people's regulatory foci into conflict, with a prevailing prevention focus dampening promotion focused responses.

Another possible explanation arises from differences in the ways in which the two regulatory systems typically operate in social contexts. The studies may have made it difficult for promotion focus effects to emerge, especially with respect to a relationship context. For example, individual differences in approach motivation are likely to reflect differences in the degree to which potentially rewarding events are actively sought after, which is thought to be related to an increase in positive affect (e.g., Gable et al., 2000). The present studies did not allow for such an increased exposure process. Instead, they provided participants with preformatted situations and asked participants to respond to them. This may work well to demonstrate promotion focus effects in non-relationship relevant contexts (e.g., Idson et al., 2000), but may not bring forth the joy that promotion focused persons feel while actively pursuing desirable 
outcomes or interactions in social contexts, or the disappointment when such outcomes are not attained.

The question that remains to be answered is why, in Study 3, neither chronic regulatory focus alone nor the prime alone affected participants' recall of regulatory focus congruent information. That is, chronically and primed promotion focused participants did not recall more approach behaviors and/or positive outcomes than did low promotion focused participants, and chronically and primed prevention focused participants did not recall more avoidance behaviors and/or negative outcomes. These null results may be due to the prime, which was adapted from a procedure by Higgins et al. (1994). It asked participants to describe their hopes and goals vs. their duties and obligations in their relationships, and how they have changed over time. In so doing, participants may have thought about a specific relationship involving a particular regulatory focus, which may have interfered with the prime. Thus, Higgins et al.'s (1994) procedure may not work equally well in a relationships context.

\section{Exploratory Analyses and Unexpected Findings}

A supplementary purpose of Study 3 was to explore how chronic regulatory focus orientations may interact with situational activation of regulatory focus. Interestingly, when a prevention focused state was momentarily activated in participants, those who were low in chronic prevention focus recalled more positive outcome information than those who were chronically high in prevention focus. Although this result was not hypothesized, the finding that highly prevention focused participants would recall less positive outcomes than those low in prevention focus in a situation that 
makes prevention concerns salient is consistent with the notion that highly prevention focused people should attend more to negative outcomes and less to positive outcomes. Why might participants with relatively inaccessible chronic prevention concerns (i.e., those who were low in chronic prevention focus) recall more positive outcome information after being exposed to a prevention prime? Little is known about circumstances that activate regulatory foci in people with chronically inaccessible regulatory focus concerns. People low in chronic prevention focus may be relatively indifferent to the absence or presence of aversive outcomes. However, certain situations could activate one or the other regulatory focus system in most people. For example, once negative outcomes are made salient to chronically low prevention focused persons, they may try to move away from a prevention focused state and seek to regain their earlier equilibrium by focusing on positive information. The strategies that people use to move from one regulatory focus state to another (or to avoid moving from one to another) in order to find their "comfort zone" is worthy of future investigation.

When interpreting the recalled episodes separately by prime condition, it was found that, compared to chronically low promotion focused participants, those high in chronic promotion focus recalled more aversive outcome information when prevention concerns were situationally activated. Perhaps this finding can be explained in terms of an ironic rebound effect, which refers to a subsequent preoccupation with unwanted thoughts that one attempts initially to inhibit (Wegner, Schneider, \& Carter, 1987). For example, research on stereotypes suggests that people may try to actively inhibit stereotypic, unwanted thoughts before they can impact one's judgment or behavior. However, these 
thoughts are likely to subsequently resurface and be even more persistent than if they had never been suppressed (Macrae, Bodenhausen, Milne, \& Jetten, 1994). Similarly, in a situation that activates prevention concerns, chronically promotion focused people may initially try to suppress these concerns because they may perceive them as a threat to efficient self-regulation towards positive outcomes. They may then experience an exacerbation of the initially suppressed thoughts, which may have been reflected in an increased recall of negative outcome information in Study 3.

Two unexpected gender interactions are noteworthy. In Study 2, women reported more happiness-related emotions in response to a nonloss than men, suggesting that they experience nonloss situations in relationships (i.e., the absence of negative outcomes) more intensely than men. In Study 3, women who were high in chronic prevention focus recalled less positive outcome information than women low in prevention focus, suggesting that highly prevention focused women attend less to positive outcomes in relationships. These findings may suggest that women may be more prevention focused in relationships. This interpretation seems consistent with evidence that women exhibit higher interdependence than men in the relational domain (Gabriel \& Gardner, 1999; Cross \& Madson, 1997), and, in support of this premise, Lee et al. (2000) found that individuals with a dominant interdependent self are more prevention focused.

\section{Limitations}

Several limitations of the present research must be acknowledged. First, problems associated with the design of the scenarios may have interfered with participants' regulatory focus for reasons elaborated earlier in this discussion. Second, because 
participants in Studies 1 and 2 were not required to be dating and were responding to hypothetical dating partners, the generalizability of these results to people involved in ongoing romantic relationships may be somewhat limited. Third, the dependent measures in Studies 1 and 2 asked people to report their presumed probability of an outcome (Study 1) and how they would feel about the depicted scenarios (Study 2). These measures are somewhat limited in that they rely on people's predictions. In future studies, self-report as well as behavioral indicators of regulatory focus relevant tendencies should be used. Fourth, the results of Study 3 should be interpreted somewhat cautiously because no manipulation check was conducted to determine whether participants were actually in a prevention versus a promotion focused state following the priming manipulation. Fifth, to support construct validity of the relatively new measure of regulatory focus that was used in all of the present studies (Lockwood et al., 2002), this scale was correlated with a measure by Higgins et al. (2001) that assesses individuals' subjective histories of success or failure in promotion and prevention self-regulation. Even though the prevention subscales of the two measures did not correlate with each other, this does not necessarily cast doubt onto the validity of Lockwood et al.'s (2002) measure, given the face validity of the items in this scale. Finally, given the design of the studies, median splits were performed on participants' chronic regulatory focus scores to divide participants into high vs. low promotion and prevention focused. One possible problem with this approach is that the meaning of "high" and "low" might be restricted to the particular samples in these studies. Another potential problem related to dichotomizing continuous variables is a potential loss of variance accounted for by the original variables (e.g., Cohen, 1983). It is 
assumed, however, that the sample sizes in the present research were large enough so that the median splits were not likely to reduce power. 


\section{CONCLUSIONS AND FUTURE DIRECTIONS}

The present research represents an initial attempt to extend regulatory focus theory into the context of romantic relationships. It appears that this attempt has been successful for the prevention focus system in association with negative events. Across two studies (Study 1 and 2), evidence was found that individual differences in chronic prevention focus affect the ways in which people respond to negative events in relationships, just as predicted by regulatory focus theory. No support was obtained for prevention focus processes in association with positive outcomes, and predictions related to the promotion focus system were also not supported. Some of the issues that may be responsible for this lack of support have been discussed above. In particular, the promotion focus system might be less amenable to investigation in cross-sectional laboratory studies. Clearly, these issues need to be addressed in future research to understand whether and how regulatory focus systems function in close relationships. Within limits, the present results do, however, indicate that investigating relationships from a regulatory focus framework may allow us to learn more about motivation in social contexts. Wanting to have a happy relationship appears to be different from not wanting to have an unhappy one.

The examination of regulatory foci in romantic relationships may also have practical implications for the effectiveness of health-related persuasive messages. For example, messages calling for protection use in an attempt to reduce STDs or unwanted pregnancies that highlight the avoidance of negative outcomes may appeal to people's security goals, and may thus be effective for people with a prevention focus in 
relationships. In contrast, messages that highlight the attainment of positive outcomes might appeal to peoples' nurturance goals (e.g., the promotion of a caring, responsible relationship through the use of protection), and be more effective for people with a promotion focus in relationships.

According to Higgins (1998), regulatory focus is a dynamic, malleable construct. In ongoing relationships, one member of a couple may affect the other's chronic level of promotion or prevention focus, or how frequently he or she adopts a situational promotion or prevention focus. Shah (2003), for example, has confirmed that representations of significant others can implicitly affect an individual's own regulatory focus. The processes by which partners' respective orientations may interact with each other, and how these interactions may shape important relationship outcomes seem to be a rich source of future investigation. Diary studies could prove useful for these purposes.

The association between motivational orientations and perceived relationship satisfaction or quality should also receive attention in future research. The present research, for example, found that a promotion focus was related to higher relationship quality, whereas a prevention focus was related to lowered relationship quality. It would be useful to examine potential factors that mediate and/or moderate this association. Because of their vigilance to avoiding negative outcomes, prevention focused people may notice and place greater weight on their partners' negative attributes and behaviors during interactions, which might lead them to experience lower relationship quality. Promotion-focused individuals, in contrast, might perceive greater relationship quality due to their stronger focus on achieving positive relationship outcomes. Because they are 
more attuned to the presence and absence of positive outcomes, promotion-focused people might notice and place more emphasis on their partners' positive attributes or behaviors during interactions. Giving more weight to positive features in the relationship may allow promotion focused people to reframe specific, potentially negative perceptions of their partner so that they develop more positive views of their partner. Neff and Karney (2003) have recently reported that a tendency to view positive perceptions as more important than negative perceptions predicts higher marital satisfaction, and have called researchers to investigate the source of this ability to reframe specific perceptions. Regulatory focus may be one of the factors that influences people's ability to organize specific perceptions of their partner and events in the relationship, for better or worse. 


\section{NOTES}

1. Socialization experiences may also amplify or reinforce existing genetic differences. For example, research has shown a positive relation between a chronic promotion focus and components of the BAS (Higgins et al., 2001). Thus, an individual with a low approach activation threshold (i.e., higher scores on the BAS) who experiences a parenting mode of encouraging accomplishment and risk-taking may acquire a very strong promotion focus. Conversely, an individual with a high neurobiological sensitivity to negative stimuli (i.e., higher scores on the BIS) can be expected to develop a very strong prevention focus if he or she experiences overprotective and punishing parenting.

2. It was assumed that participants needed to have at least some kind of experience with romantic partners in order to be able to relate to the scenarios used in the study.

3. The decision to use orthogonal rotation was based on regulatory focus theory and research that suggests that promotion and prevention foci are independent systems. The analysis was repeated with oblique rotation, and results did not change.

4. The significant results of Study 1 did not change when these variables were included as covariates in the analyses.

5. Since the dependent variables are conceptually related, a multivariate repeated measures analysis of variance (MANOVA) would be an alternative to the present analyses. In choosing the statistical analyses for this study, previous studies of regulatory focus were consulted (e.g., Idson et al., 2001, Higgins et al., 1994; Higgins \& Tykocinski; Lee et al., 2001). To make the present study and results comparable with previous investigations, a mixed design analysis of variance has been selected.

6. To provide an estimate of the percentage of variance in the dependent variable that can be predicted from the independent variable, and to offer a frame of reference for the meaning of the relevant statistically significant results, the partial eta square statistic $\left(\eta^{2}\right)$ was computed in all three studies.

7. It should be noted that the current results were significant with both the traditional $\mathrm{F}$ values and conservative degree of freedom adjustment. Because the Mauchley sphericity tests were significant (i.e., the sphericity assumption was violated), Geisser and Greenhouse's (1958) procedure was used to adjust the degrees of freedom for all within-subjects F-tests in the analyses. This procedure corrects for the positive bias in the within-subjects F-values caused by violation of the sphericity assumption, thereby minimizing the probability of a Type-I error. 
8. The significant results of Study 2 did not change when these variables were included as covariates in the analyses.

9. A repeated measures multivariate analysis of variance (MANOVA) could also have been conducted in this study. Given that the dependent variables were so highly correlated, however, a decrease in power in MANOVA was expected (Tabachnik \& Fidell, 2001). Thus, the current analyses were performed.

10. This requirement was introduced because Study 3 was also intended to explore the potential association between regulatory focus and relationship quality.

11. Gender, attachment avoidance and anxiety, extraversion and neuroticism, and neutral filler items were also entered as variables in the analyses. No effects for neutral filler items were found. There was a significant interaction between avoidant attachment, prevention focus, and recall, suggesting that highly avoidant participants who were low in prevention focus recalled more positive outcome information, $F(3,133)=5.13, p=$ .004. Furthermore, a significant interaction between anxious attachment, prevention focus, and recall indicated that those low in anxiety and prevention focus recalled more positive outcome information, $F(3,133)=5.67, p=.002$. There was also a noninterpretable interaction between prime, anxious attachment, promotion focus and recall, $F(3,133)=3.12, p=.036$, and a non-interpretable interaction between anxious attachment, promotion focus, prevention focus, and recall, $F(3,133)=2.94, p=.046$. In terms of personality dimensions, there was an interaction between extraversion, prevention focus, and recall, such as that highly extraverted participants who were low in prevention focus recalled more positive outcome information, $F(1,133)=7.20, p=.001$. There was also a non-interpretable interaction between prime, extraversion, neuroticism, and recall, $F(3,133)=3.11, p=.042$. Because these interactions are of little theoretical importance to the present study, there are not discussed further. Finally, there was a significant between subjects effect for $\operatorname{sex}, F(3,147)=15.12, p<.001$, revealing that women showed better recall than men, and a significant interaction between gender, prevention focus, and recall, such as that women who were high in prevention focus recalled less positive outcome information than women low in prevention focus, $F(3$, $147)=3.81, p=.02$.

12. Follow-up analyses using a modified Bonferroni-type adjustment to decompose the marginally significant prevention focus $x$ recall interaction were performed. Simple main effect analyses showed that highly prevention focused participants recalled less positive outcome information than participants low in prevention focus, but this effect was not significant at the alpha level required by the Bonferroni-type adjustment. 


\section{REFERENCES}

Aaker, J. L., \& Lee, A. Y. (2001). "I" seek pleasures and "we" avoid pains: The role of self-regulatory goals in information processing and persuasion. Journal of Consumer Research, 28, 33-49

Atkinson, J. W. (1964). An introduction to motivation. Princeton, NJ: Van Nostrand.

Baldwin, M. W. (1992). Relational schemas and the processing of social information. Psychological Bulletin, 112, 461-484.

Bargh, J. A., \& Pietromonaco, P. (1982). Automatic information processing and social perception: The influence of trait information presented outside of conscious awareness on impression formation. Journal of Personality and Social Psychology, $43,437-449$.

Berscheid, E. (1994). Interpersonal relationships. Annual Review of Psychology, 45, 70129.

Bowlby, J. (1969). Attachment (Attachment and loss, Vol. 1). New York: Basic Books. Bowlby, J. (1973). Separation: Anxiety and anger (Attachment and loss, Vol. 2). New York: Basic Books.

Brendl, C. M., Higgins, E. T., \& Lemm, K. M. (1995). Sensitivity to varying gains and losses: The role of self-discrepancies and event framing. Journal of Personality and Social Psychology, 69, 1028-1051.

Cacioppo, J. T., \& Berntson, G. G. (1994). Relationship between attitudes and evaluative space: A critical review, with emphasis on the separability of positive and negative substrates. Psychological Bulletin, 115, 401-423. 
Cacioppo, J. T., Gardner, W. L., \& Berntson, G. G. (1999). The affect system has parallel and integrative processing components: Form follows function. Journal of Personality and Social Psychology, 76, 839-855.

Carver, C. S. (1996). Emergent integration in contemporary personality psychology. Journal of Research in Personality, 30, 319-334.

Carver, C. S., \& Scheier, M. F. (1981). Attention and self-regulation: A control-theory approach to human behavior. New York: Springer Verlag.

Carver, C. S., \& Scheier, M. F. (1990). Principles of self-regulation: Action and emotion. In E. T. Higgins, \& R. M. Sorrentino (Eds.), Handbook of motivation and cognition: Foundations of social behavior (Vol. 2, pp. 3-52). New York: Guilford Press.

Carver, C. S., Sutton, S. K., \& Scheier, M. F. (2000). Action, emotion, and personality: Emerging conceptual integration. Personality and Social Psychology Bulletin, 26, $741-751$

Carver, C. S., \& White, T. L. (1994). Behavioral inhibition, behavioral activation, and affective responses to impending reward and punishment: The BIS/BAS scales. Journal of Personality and Social Psychology, 67, 319-333.

Cohen, J. (1988). Statistical power analyses for the behavioral sciences $\left(2^{\text {nd }} \mathrm{ed}.\right)$. Hillsdale, NJ: Lawrence Erlbaum Associates.

Collins, N. L., \& Read, S. J. (1994). Cognitive representations of attachment: The structure and function of working models. In K. Bartholomew, \& D. Perlman (Eds.), Attachment processes in adulthood (pp. 53-90). London: Jessica Kingsley. 
Cross, S. E., \& Madson, L. (1997). Models of the self: Self-construals and gender. Psychological Bulletin, 122, 5-37.

Crowe, E., \& Higgins, E. T. (1997). Regulatory focus and strategic inclinations: Promotion and prevention decision-making. Organizational Behavior and Human Decision Processes, 69, 117-132.

Derryberry, D., \& Reed, M. A. (1994). Temperament and attention: Orienting toward and away from positive and negative signals. Journal of Personality and Social Psychology, 66, 1128-1139.

Elliot, A. J. (1999). Approach and avoidance motivation and achievement goals. Educational Psychologist, 34, 169-189.

Elliot, A. J., \& Church, M.A. (1997). A hierarchical model of approach and avoidance achievement motivation. Journal of Personality and Social Psychology, 72, 218 232.

Elliot, A. J., \& Sheldon, K. M. (1998). Avoidance personal goals and the personalityillness relationship. Journal of Personality and Social Psychology, 75, 1282-1299.

Fletcher, G. J. O., Simpson J. A., \& Thomas G. (2000). The measurement of perceived relationship quality components: A confirmatory factor analytic approach. Personality and Social Psychology Bulletin, 26, 340-354.

Förster, J., Higgins, E. T., \& Idson, L. C. (1998). Approach and avoidance strength during goal attainment: Regulatory focus and the "goal looms larger" effect. Journal of Personality and Social Psychology, 75, 1115-1131.

Gable, S. L. (2003). Approach and avoidance social motives and goals. Unpublished 
manuscript, UCLA, Los Angeles, CA.

Gable, S. L., \& Reis, H. T. (2001). Appetitive and aversive social interaction. In J. H. Harvey \& A. E. Wenzel (Eds.), Close romantic relationship maintenance and enhancement (pp. 169-194). Mahwah, NJ: Erlbaum.

Gable, S. L., Reis, H. T., \& Elliot, A. J. (2000). Behavioral activation and inhibition in everyday life. Journal of Personality and Social Psychology, 78, 1135-1149.

Gabriel, S. \& Gardner, W. L. (1999). Are there "his" and "hers" types of interdependence? The implications of gender differences in collective versus relational interdependence for affect, behavior, and cognition. Journal of Personality and Social Psychology, 77, 642-655.

Goldberg, L. R. (1990). An alternative description of personality: The Big Five factor structure. Journal of Personality and Social Psychology, 59, 1216-1229.

Gray, J. A. (1987). The neuropsychology of emotion and personality. Cognitive Neurochemistry, 395, 171-190.

Gray, J. A. (1990). Brain systems that mediate both emotion and cognition. Cognition and Emotion, 4, 269-288.

Gray, J. A. (1994). Three fundamental emotion systems. In P. Ekman, \& R. J. Davidson (Eds.), The nature of emotion (pp. 243-247). New York: Oxford University Press.

Harmon-Jones, E., \& Allen, J. J. B. (1997). Behavioral activation sensitivity and resting frontal EEG asymmetry: Covariation of putative indicators related to risk for mood disorders. Journal of Abnormal Psychology, 106, 159-163. 
Higgins, E. T. (1997). Beyond pleasure and pain. American Psychologist, 52, 12801300.

Higgins, E. T. (1998). Promotion and prevention: Regulatory focus as a motivational principle. In M. P. Zanna (Ed.), Advances in experimental social psychology (Vol. 30, pp. 1-46). New York: Academic Press.

Higgins, E. T. (2000). Making a good decision: Value from fit. American Psychologist, $55,1217-1233$

Higgins, E. T., Friedman, R. S., Harlow, R. E., Idson, L. C., Ayduk, O. N., \& Taylor, A. (2001). Achievement orientations from subjective histories of success: Promotion pride versus prevention pride. European Journal of Social Psychology, 31, 3-23.

Higgins, E., Roney, C. J. R., Crowe, E., \& Hymes, C. (1994). Ideal versus ought predilections for approach and avoidance distinct self-regulatory systems. Journal of Personality and Social Psychology, 66, 276-286.

Higgins, E. T., Shah, J., \& Friedman, R. (1997). Emotional responses to goal attainment: Strength of regulatory focus as moderator. Journal of Personality and Social Psychology, 72, 515-525.

Higgins, E. T., \& Silberman, I. (1998). Development of regulatory focus: Promotion and prevention as ways of living. In J. Heckhausen \& C. S. Dweck (Eds.), Motivation and self-regulation across the life span (pp. 78-113). New York: Cambridge University Press. 
Higgins, E. T., \& Tykocinski, O. (1992). Self-discrepancies and biographical memory: Personality and cognition at the level of psychological situation. Personality and Social Psychology Bulletin, 18, 527-535.

Holland, B. S., \& Copenhaver, M. (1988). Improved Bonferroni-type multiple testing procedures. Psychological Bulletin, 104, 145-149.

Holmes, J. G. (2000). Social relationships: the nature and function of relational schemas. European Journal of Social Psychology, 30, 447-495.

Idson, L.C., Liberman, N., \& Higgins, T.E. (2000). Distinguishing gains from nonlosses and losses from nongains: a regulatory focus perspective on hedonic intensity. Journal of Experimental Social Psychology, 36, 252-274.

Keppel, G. (1991). Design and analysis. A researcher's handbook ( $3^{\text {rd }}$ ed.). Upper Saddle River, NJ: Prentice Hall.

Kluger, A. N. (2000). Needs, self-regulation, and risk taking. Paper presented at the 15th annual convention of the Society for Industrial and Organizational Psychology, New Orleans, LA.

Lee, A. Y., \& Aaker, J. L. (2004). Bringing the frame into focus: The influence of regulatory fit on processing fluency and persuasion. Journal of Personality and Social Psychology, 86, 205-218.

Lee, A. Y., Aaker, J. L., \& Gardner, W. L. (2000). The pleasures and pains of distinct self-construals: the role of interdependence in regulatory focus. Journal of Personality and Social Psychology, 78, 1122-1134. 
Liberman, N., Idson, L. C., Camacho, C. J., \& Higgins, E. T. (1999). Promotion and prevention choices between stability and change. Journal of Personality and Social Psychology, 77, 1135-1145.

Liberman, N., Molden, D. C., Idson, L. C., \& Higgins, E. T. (2001). Promotion and prevention focus on alternative hypotheses: Implications for attributional functions. Journal of Personality and Social Psychology, 80, 5-18.

Lockwood, P., Jordan, C. H., \& Kunda, Z. (2002). Motivation by positive or negative role models: Regulatory focus determines who will best inspire us. Journal of Personality and Social Psychology, 83, 854-864.

Macrae, C. N., Bodenhausen, G. V., Milne, A. B., \& Jetten, J. (1994). Out of mind but back in sight: Stereotypes on the rebound. Journal of Personality and Social Psychology, 67, 808-817.

Manian, N. (2000). Developmental determinants of goal orientation: The role of parenting and temperament. Unpublished doctoral dissertation, University of Wisconsin, Madison.

Maslow, A. (1955). Deficiency motivation and growth motivation. In M. Jones (Ed.), Nebraska symposium \#1 on values (pp.1-30). Lincoln, Nebraska: Univ. of Nebraska Press, 1955.

Mikulincer, M. (1998). Attachment working models and the sense of trust: An exploration of interaction goals and affect regulation. Journal of Personality and Social Psychology, 74, 1209-1224. 
Mikulincer, M., \& Shaver, P. R. (2001). Attachment theory and intergroup bias:

Evidence that priming the secure base schema attenuates negative reactions to outgroups. Journal of Personality and Social Psychology, 81, 97-115.

Neff, L. A., \& Karney, B. R. (2003). The dynamic structure of relationship perceptions: differential importance as a strategy of relationship maintenance. Personality and Social Psychology Bulletin, 29, 1433-1446.

Reis, H. T., \& Gable, S. L. (2003). Toward a positive psychology of relationships. In C.L. Keyes \& J. Haidt (Eds.). Flourishing: The positive person and the good life. (pp. 129-159). Washington, DC: American Psychological Association.

Rogers, C. (1960). A therapist's view of personal goals. Wallingford: Pendle Hill.

Shah, J. (2003). The motivational looking glass: How significant others implicitly affect goal appraisals. Journal of Personality and Social Psychology, 85, 424-439.

Shah, J., Higgins, E. T., \& Friedman, R. (1998). Performance incentives and means: How regulatory focus influences goal attainment. Journal of Personality and Social Psychology, 73, 447-458.

Simpson, J. A., Rholes, S. W., \& Phillips, D. (1996). Conflict in close relationships: An attachment perspective. Journal of Personality and Social Psychology, 71, 899914.

Smith, E. R., Murphy, J., \& Coats, S. (1999). Attachment to groups: Theory and management. Journal of Personality \& Social Psychology, 77, 94-110.

Sobotka, S. S., Davidson, R. J., \& Senulis, J. A. (1992). Anterior brain electrical 
asymmetries in response to reward and punishment. Electroencephalography and Clinical Neurophysiology, 83, 236-247.

Srull, T. K., \& Wyer, R. S. (1979). The role of category accessibility in the interpretation of information about persons: Some determinants and implications. Journal of Personality and Social Psychology, 37, 1660-1662.

Sutton, S. K., \& Davidson, R. J. (1997). Prefrontal brain asymmetry: A biological substrate of the behavioral approach and inhibition systems. Psychological Science, 8, 204-210.

Wegner, D. M., Schneider, D. J., Carter, S. R., \& White, T. L. (1987). Paradoxical effects of thought suppression. Journal of Personality and Social Psychology, 53, $5-13$.

Winer, B. J., Brown, D. R., \& Michels, K. M. (1991). Statistical principles in experimental design. New York, NY: McGraw-Hill. 


\section{APPENDIX A}

\section{BACKGROUND SURVEY}

Please answer the following questions on the page.

1. Are you a male or a female? (Check one).

Male
Female

2. How old are you?

3. How many months have you dated your current partner?

4. What is your current dating status? (Check one).

dating my current partner and others
dating my current partner and no one else
engaged
married

5. Which of the following sets of circles best describes you and your current dating partner? (Circle the correct set of circles).

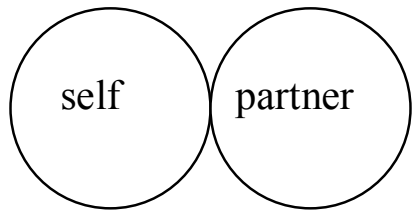

1

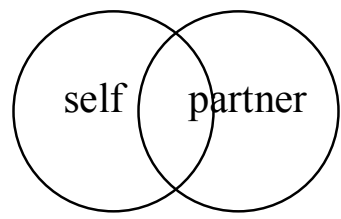

4

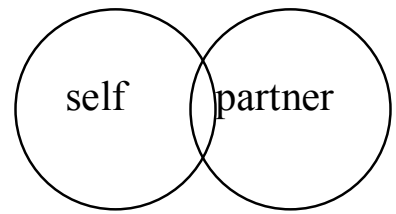

2

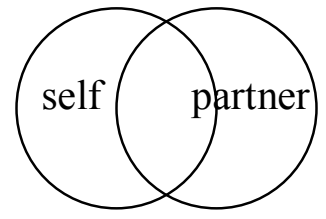

5

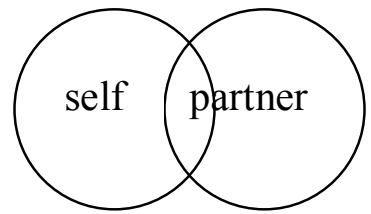

3

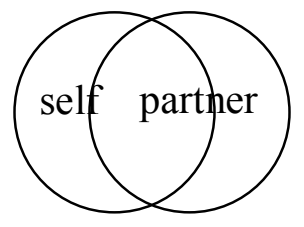

6

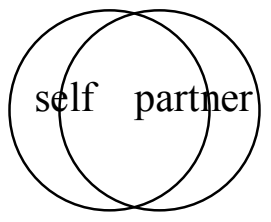

7 


\section{APPENDIX B}

\section{Lockwood's Promotion and prevention scale (modified)}

Using the scale below, please indicate the appropriate number on your scantron.

$\begin{array}{lllllllll}1 & 2 & 3 & 4 & 5 & 6 & 7 & 8 & 9 \\ \begin{array}{l}\text { Not at all } \\ \text { true of }\end{array} & & & & & & & & \begin{array}{l}\text { Very true } \\ \text { of me }\end{array}\end{array}$

me

1. In general, I am focused on preventing negative events in my relationship.

2. I am anxious that I will fall short of my responsibilities and obligations in my relationship.

3. I frequently imagine how I will achieve my hopes and aspirations in my relationship.

4. I often think about what my relationship might become in the future.

5. I often think about what my relationship would ideally be like in the future.

6. I typically focus on the success (e.g., the happiness) I hope to achieve in my relationship.

7. I often worry that I will fail to accomplish my relationship goals.

8. I often think about how I will achieve relationship success.

9. I often imagine myself experiencing bad things that I fear might happen to my relationship.

10. I frequently think about how I can prevent failures in my relationship.

11. I am more oriented toward preventing losses in my relationship than I am toward achieving gains.

12. My major goal right now is to pursue my ambitions in my relationship.

13. My major goal right now is to avoid my relationship becoming a failure.

14. I am primarily striving to reach my "ideal relationship"—-to fulfill my hopes, wishes, and aspirations.

15. I am primarily striving to reach what my relationship "ought" to be like- to fulfill my duties, responsibilities, and obligations.

16. In general, I am focused on achieving positive outcomes in my relationship.

17. I often imagine myself experiencing good things that I hope will happen in my relationship.

18. Overall, I am more oriented toward achieving success than preventing failure in my relationship. 


\section{APPENDIX C}

\section{ADULT ATTACHMENT QUESTIONNAIRE (AAQ)}

Please indicate how you typically feel toward romantic (dating) partners in general. Keep in mind that there are no right or wrong answers. Use the 7-point scale provided below and darken the appropriate number for each item on the scantron.

\begin{tabular}{ccccccc}
1 & 2 & 3 & 4 & 5 & 6 & 7 \\
\hline $\begin{array}{l}\text { I strongly } \\
\text { disagree }\end{array}$ & & & & & & \\
\hline
\end{tabular}

1. I find it relatively easy to get close to others.

2. I'm not very comfortable having to depend on other people.

3. I'm comfortable having others depend on me.

4. I rarely worry about being abandoned by others.

5. I don't like people getting too close to me.

6. I'm somewhat uncomfortable being too close to others.

7. I find it difficult to trust others completely.

8. I'm nervous whenever anyone gets too close to me.

9. Others often want me to be more intimate than I feel comfortable being.

10. Others often are reluctant to get as close as I would like.

11. I often worry that my partner(s) don't really love me.

12. I rarely worry about my partner(s) leaving me.

13. I often want to merge completely with others, and this desire sometimes scares them away.

14. I'm confident others would never hurt me by suddenly ending our relationship.

15. I usually want more closeness and intimacy than others do.

16. The thought of being left by others rarely enters my mind.

17. I'm confident that my partner(s) love me just as much as I love them. 


\section{APPENDIX D}

\section{Big Five Personality Profile}

For each of the following items honestly indicate whether you agree or disagree that each statement applies to your personality. Use the following scale.

\begin{tabular}{ccccc}
1 & 2 & 3 & 4 & 5 \\
\hline $\begin{array}{l}\text { disagree } \\
\text { strongly }\end{array}$ & $\begin{array}{l}\text { disagree } \\
\text { a little }\end{array}$ & $\begin{array}{l}\text { neither agree } \\
\text { nor disagree }\end{array}$ & $\begin{array}{l}\text { agree } \\
\text { a little }\end{array}$ & $\begin{array}{c}\text { agree } \\
\text { strongly }\end{array}$
\end{tabular}

1. I am outgoing, sociable

2. I tend to find fault with others

3. I am a reliable worker

4. I remain calm in intense situations

5. I value artistic, aesthetic experiences

6. I am reserved

7. I am considerate and kind to almost everyone

8. I can be somewhat careless

9. I am relaxed, handle stress well

10. I prefer work that is routine and simple

11. I am full of energy

12. I can be cold and aloof

13. I do things efficiently

14. I get nervous easily

15. I have an active imagination

16. I am sometimes shy, inhibited

17. I like to cooperate with others

18. I tend to be disorganized

19. I am emotionally stable, not easily upset

20. I have few artistic interests

21. I am talkative

22. I am sometimes rude to others

23. I do a thorough job

24. I am depressed, blue

25. I am sophisticated in art, music, or literature

26. I tend to be quiet

27. I am generally trusting

28. I am lazy at times

29. I worry a lot

30. I am ingenious, a deep thinker

31 . I generate a lot of enthusiasm

32. I have a forgiving nature

33. I am easily distracted

34. I can be tense

35. I am inventive 


\section{APPENDIX E}

Vignette - Study 1 (Positive partner response condition)

Imagine the following situation:

Greg and Mona are dating partners and have plans for a romantic dinner-for-two tonight. Mona's best friend has had some serious trouble at work recently, and asks Mona to meet with her to talk about her problems. Although Mona feels bad because she had dinner plans with Greg, she agrees to meet because she wants to be there for her friend. Mona calls Greg on the phone to tell him about her friend's trouble, and suggests having the dinner tomorrow instead. When she calls, Greg is in the midst of preparing the romantic dinner...

There are two possible outcomes to this scenario. Please read both outcomes, and then indicate the likelihood that each outcome could occur.

Outcome 1: Greg gladly agrees to postpone the dinner. It makes him happy to know that Mona is being such a good friend, and he looks forward to the dinner with her tomorrow.

Outcome 2: Greg is not exactly happy, but he's pleased that they'll see each other tomorrow. He's satisfied knowing that their dinner plans are only postponed, and not cancelled.

130. From your perspective, how likely is it that outcome 1 will occur?

\begin{tabular}{|c|c|c|}
\hline & 2 & \\
\hline
\end{tabular}

131. From your perspective, how likely is that outcome 2 will occur?

$\begin{array}{llllllll}0 & 1 & 2 & 3 & 4 & 5 & 6 & 7\end{array}$

Not likely at all

Very likely 


\section{Vignette - Study 1 (Negative partner response condition) \\ Imagine the following situation:}

Greg and Mona are dating partners and have plans for a romantic dinner-for-two tonight. Mona's best friend has had some serious trouble at work recently, and asks Mona to meet with her to talk about her problems. Although Mona feels bad because she had dinner plans with Greg, she agrees to meet because she wants to be there for her friend. Mona calls Greg on the phone to tell him about her friend's trouble, and suggests having the dinner tomorrow instead. When she calls, Greg is in the midst of preparing the romantic dinner...

There are two possible outcomes to this scenario. Please read both outcomes, and then indicate the likelihood that each outcome could occur.

Outcome 1: Greg feels dumped, and is angry with Mona. He's agitated because he thinks her friends are more important to Mona than he is, and doesn't want to see her for the rest of the weekend.

Outcome 2: Greg is disappointed, but not angry. Although they'll have the dinner together tomorrow, he's a little sad because he was really looking forward to spending time with Mona tonight.

130. From your perspective, how likely is it that outcome 1 will occur?

12

3

4

5

6

7

Not likely at all

Very likely

131. From your perspective, how likely is that outcome 2 will occur?

$\begin{array}{llllllll}0 & 1 & 2 & 3 & 4 & 5 & 6 & 7\end{array}$

Not likely at all

Very likely 


\begin{abstract}
APPENDIX F
Vignettes - Study 2

Please imagine the following situation: You have to take an important test at school on Friday. If you fail, you can simply repeat it Saturday. However, your partner has invited you for a vacation, and the plane leaves Friday evening.
\end{abstract}

Gain condition: You take the test, and pass it. Now you will go on the vacation and have a great time with your partner.

Non-gain condition: You take the test, and don't pass it. Now you won't get to go on the vacation and you will miss out on a great time with your partner.

Loss condition: You take the test, and fail it. Now you have to disappoint your partner because you have to cancel the trip in order to retake the test.

Non-loss condition: You take the test, and don't fail it. Now you don't have to disappoint your partner by canceling the trip.

Please rate the extent to which you felt each emotion when you realized that you could/could not go on the vacation with your partner:

$\begin{array}{cccccccccc}0 & 1 & 2 & 3 & 4 & 5 & 6 & 7 & 8 & 9 \\ \text { Not at all } & & & & & & & & & \text { A great deal }\end{array}$

1. Angry

2. Sad

3. Happy

4. Content (Satisfied)

5. Agitated (Restless)

6. Cheerful

7. Disappointed

8. Pleased 


\section{APPENDIX G}

\section{Perceived Relationship Quality Components Inventory}

Instructions: Please indicate what your current partner/relationship is like, answering each question that follows. Use this scale when answering each question:

\begin{tabular}{lllllll}
1 & 2 & 3 & 4 & 5 & 6 & 7 \\
\hline
\end{tabular}

not at all

extremely

1. How satisfied are you with your relationship?

2. How content are you with your relationship?

3. How happy are you with your relationship?

4. How committed are you to your relationship?

5. How dedicated are you to your relationship?

6 . How devoted are you to your relationship?

7. How intimate is your relationship?

8. How close is your relationship?

9. How connected are you to your partner?

10. How much do you trust your partner?

11. How much can you count on your partner?

12. How dependable is your partner?

13. How passionate is your relationship?

14. How lustful is your relationship?

15. How sexually intense is your relationship?

16. How much do you love your partner?

17. How much do you adore your partner?

18. How much do you cherish your partner? 


\section{APPENDIX H}

\section{Promotion prime:}

Instructions: Please describe in a paragraph or two your hopes and goals for your current dating partner and romantic relationship. After that, think about how your hopes and goals for your current dating partner/romantic relationship have changed compared to the ones you had when you first started dating people.

\section{Promotion prime:}

Instructions: Please describe in a paragraph or two your sense of duty, responsibility, or obligation that you have to your current dating partner or in your current romantic relationship. After that, think about how your sense of duty, responsibility, or obligation for your current dating partner/romantic relationship has changed compared to the one you had when you first started dating people. 


\section{APPENDIX I}

Instructions: The following are episodes that were pulled from the diary of a Texas A\&M undergraduate student named Jamie. The episodes describe events that occurred over 4 days in Jamie's life. Some episodes talk about general life events, and others involve Jamie's boyfriend Jim. Please read the episodes slowly and carefully, and form an impression of what these days were like for Jamie. (Target person was male for male participants, and female for female participants).

Day 1:

- I dislike unresolved issues, so I asked him to go outside for a walk so that we could calmly talk about the problem.

- I don't want to be too far away from Jim, so I didn't apply to any grad schools on the East coast.

- Because I want to make him happy, I surprised him with a ticket to a game and coupons for the Fox and Hound so that he can have a good time with his buddies.

- I wanted us to spend time together, so I turned down my friends' invitation to a girls-night-out at the Dixie Chicken to be able to go to the movies with Jim.

- Because I overslept this morning, I was late for class. I didn't have time to brown bag my lunch, so I went to cafeteria and bought a sandwich. (Filler item)

Day 2:

- Because I wanted to spend time with Jim, I ran a few errands for him this afternoon, so that he could be free for a romantic dinner tonight.

- I don't want us to ignore our problems, so I'll write him a letter to let him know how I feel about it, and to assure him that I still care about him.

- I want us to have a happy relationship without any arguments, so I kept it from Jim that the guy from my math class asked me out the other day.

- I didn't want to upset Jim, so I didn't tell him that I ran into my ex-boyfriend at Post Oaks Mall earlier today and that we had a quick lunch together to catch up. 
- I went to the post office today to buy some stamps and mail a birthday package to my sister. Bought a cappuccino afterwards and hit the library to study until about 6 PM. (Filler item).

Day 3:

- I don't want our relationship to become boring, so I've signed us up for a water skiing course.

- I want him to know that I believe that he's capable of taking care of himself, so I didn't say anything about the mess in his kitchen.

- Jim has the flu and couldn't come to our friend Joe's birthday party. Because I wanted to cheer him up, I left the party early and brought him some of his favorite party food.

- My family didn't invite Jim to our reunion next month. I don't want him to feel as if my family does not accept him, so I decided to not mention the reunion at all to him.

- I went to buy new fall clothes today and a couple of CDs. I've got to budget my money carefully now for the rest of the month. (Filler item).

\section{Day 4:}

- Because I want us to have a trusting relationship, I told Jim about the phone call from my ex-boyfriend who wanted advice on his problems at work.

- I don't want Jim to feel smothered, so I encouraged him to go on the fishing trip that all of his friends are going on next weekend.

- I want Jim to trust me, so I didn't tell his mom that he flunked out of his math class when she asked me about it this morning.

- I didn't want to say something that I might later regret, so I left the apartment and went over to a friend's place.

- Today a few people from my statistics lab and I checked out the new pizza place that my friends recommended. (Filler item). 


\section{VITA}

Name: Heike A. Winterheld

Address: Texas A\&M University

Department of Psychology

College Station, TX 77843-4235

E-mail: HeikeWin@tamu.edu

$\underline{\text { Education }}$

Tierarzt, Ludwig-Maximilians-University, Munich, Germany, 1996

\section{Publications and Presentations}

Simpson, J. A., Winterheld, H. A., \& Chen, J. Y. (in press). Personality and relationships: A temperament perspective. To appear in A. Vangelisti, \& D. Pearlman (Eds.), The Cambridge handbook of personal relationships. New York: Cambridge University Press.

Simpson, J. A., Wilson, C. L., \& Winterheld, H. A. (2004). Sociosexuality and romantic relationships. In J. H. Harvey, A. Wenzel, \& S. Sprecher (Eds.), Handbook of sexuality in close relationships (pp. 87-112). Mahwah, NJ: Erlbaum.

Winterheld, H. A., Simpson, J. A., Rholes, W. S. (2003). Attachment style and regulatory focus in romantic relationships. Presented at the 4th Annual Meeting of the Society for Personality and Social Psychology, Los Angeles, CA.

Kim, P. S., Ando, M., Hishinuma, E. S., Nishimura, S. T., Winterheld, H. A., So, J. H., Miyamoto, R. H., Else, I. R. N. (2001). A pilot study on the mental health of adolescents and youth at the Hawaii Youth Correctional Facility. (Tech. Rep. No. 2b). Honolulu, HI: University of Hawaii, Department of Psychiatry. 